\title{
Nanoparticle exposure and hazard in the ceramic industry: an overview of potential sources, toxicity and health effects
}

Authors: Maria João Bessa ${ }^{1,2,3}$, Fátima Brandão ${ }^{1,2}$, Mar Viana ${ }^{4}$, João F. Gomes ${ }^{5,6}$, Eliseo Monfort $^{7}$, Flemming R. Cassee ${ }^{8,9}$, Sónia Fraga ${ }^{1,2^{*}}$, João Paulo Teixeira ${ }^{1,2}$

Affiliations: ${ }^{1}$ Instituto Nacional de Saúde Doutor Ricardo Jorge, Departamento de Saúde Ambiental, Porto, Portugal; ${ }^{2}$ EPIUnit - Instituto de Saúde Pública, Universidade do Porto, Porto, Portugal; ${ }^{3}$ Instituto de Ciências Biomédicas Abel Salazar, Universidade do Porto, Porto, Portugal; ${ }^{4}$ Institute of Environmental Assessment and Water Research (IDÆA-CSIC), Barcelona, Spain; ${ }^{5}$ CERENA, Centro de Recursos Naturais e Ambiente/Instituto Superior Técnico, Universidade de Lisboa, Lisboa, Portugal; ${ }^{6}$ ISEL - Instituto Superior de Engenharia de Lisboa, Lisboa, Portugal; ${ }^{7}$ Institute of Ceramic Technology (ITC), Universitat Jaume I, 12006, Castellón, Spain; ${ }^{8}$ National Institute for Public Health and the Environment, Bilthoven, The Netherlands; ${ }^{9}$ Institute for Risk Assessment Studies, Utrecht University, Utrecht, The Netherlands.

"Corresponding author: Sónia Fraga, Departamento de Saúde Ambiental, Instituto Nacional de Saúde Doutor Ricardo Jorge, Rua Alexandre Herculano, 321, 4000-055 Porto, Portugal; email: sonia.fraga@insa.min-saude.pt; phone: (+351) 223401143.

Email addresses: mjbessa8@gmail.com (M.J. Bessa); fatima.brandao988@gmail.com (F. Brandão); mar.viana@idaea.csic.es (M. Viana); jgomes@deq.isel.ipl.pt (J.F. Gomes);

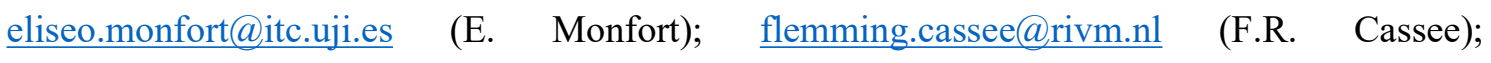
sonia.fraga@insa.min-saude.pt (S. Fraga); jpft12@gmail.com (J.P. Teixeira) 


\begin{abstract}
The ceramic industry is an industrial sector of great impact in the global economy that has been benefitting from advances in materials and processing technologies. Ceramic manufacturing has a strong potential for airborne particle formation and emission, namely of ultrafine particles (UFP) and nanoparticles (NP), meaning that workers of those industries are risk of potential exposure to these particles. At present, little is known on the impact of engineered nanoparticles (ENP) on the environment and human health and no established Occupational Exposure Limits (OEL) or specific regulations to airborne nanoparticles (ANP) exposure exist raising concerns about the possible consequences of such exposure. In this paper, we provide an overview of the current knowledge on occupational exposure to NP in the ceramic industry and their impact on human health. Possible sources and exposure scenarios, a summary of the existing methods for evaluation and monitoring of ANP in the workplace environment and proposed Nano Reference Values (NRV) for different classes of NP are presented. Case studies on occupational exposure to ANP generated at different stages of the ceramic manufacturing process are described. Finally, the toxicological potential of intentional and unintentional ANP that have been identified in the ceramic industry workplace environment is discussed based on the existing evidence from in vitro and in vivo inhalation toxicity studies.
\end{abstract}

Keywords: ceramic industry; occupational exposure; airborne nanoparticles; toxicity; human health 


\section{Funding}

This work was supported by the Portuguese Foundation for Science and Technology (FCT) through the ERA-NET SIINN project CERASAFE (SIINN/0004/2014). M.J. Bessa and F. Brandão are recipients of $\mathrm{FCT} \mathrm{PhD}$ scholarships (SFRH/BD/120646/2016 and SFRH/BD/101060/2014) under the framework of Programa Operacional Capital Humano $(\mathrm{POCH})$ and European Union funding. 


\section{Introduction}

Throughout history to the present, the ceramic industry has been offering a wide range of materials with great impact on our daily lives. Broadly, a ceramic material can be defined as an inorganic, heat-resistant material composed by both metallic and non-metallic compounds. Ceramics have a broad application from construction to consumer goods and are used in several industrial processes and cutting-edge technologies. Bricks, ceramic tiles, drainage pipes, sanitaryware, household appliances, table- and ornamentalware are some of their most wellknown applications. Due to their durability, strength, non-corrosive properties and ability to withstand very high temperatures, ceramics are also employed for specific uses (e.g. as enamels, abrasives and refractories) required in metallurgical processes, glass production and many other key processes across all industries (Pampuch, 2014). Advanced ceramics with unique mechanical, electrical and thermal properties emerged in the 80's having a huge impact in cutting-edge technologies. They are used to produce a variety of materials such as cutting tools, coatings, body armour, electrical and electronic equipment, engine parts and medical products (Marinescu, 2006; Munz and Fett, 2013). A significant number of the world's ceramic industries are located in European Union (EU) countries, with over 200,000 workers and an estimated production value of 28 billion euros per year (Cerame-Unie, 2012). Overall, EU ceramic industries account for $23 \%$ of the worldwide production, playing a significant role in the global economy (Cerame-Unie, 2012; Cerame-Unie, 2015; European Commission, 2007).

In general, the main process of ceramics manufacturing is quite straightforward. Figure 1 depicts major steps of the general manufacturing process of a ceramic product, starting with the preparation of the raw material (including addition of auxiliary agents, if needed), followed by shaping, drying, surface treatment (when applicable), firing, product finishing/sorting and packaging. As shown in Table 1, a wide range of raw materials (oxide-based and non-oxidebased), in bulk and nanoforms, are currently utilized in the ceramic industry for different purposes. Nanotechnology has already reached the ceramic sector. For many years, nanoscale ceramic materials have been used in the biomedical field as orthopaedic implants (Traykova et al., 2006). At the same time, many nanomaterials (NM) have been applied in numerous ceramic processes. The specific nanoscale features of NM (size range $1 \mathrm{~nm}-100 \mathrm{~nm}$ ) (European Commission, 2011) offer the opportunity to explore novel property combinations or improved tribological, mechanical or corrosion properties for nanoceramics and nanopowders (Table 1). Indeed, NM such as graphene, carbon nanotubes (CNT) and carbon black are used in the ceramic industry for their reinforcing ability (Ahmad et al., 2015; Liu et al., 2016; Wakamatsu and Salomao, 2010). Titania $\left(\mathrm{TiO}_{2}\right) \mathrm{NP}$ are also used for ceramic glaze, in tiles or as stiffening fillers (Cain and Morrell, 2001; da Silva et al., 2017; Manivasakan et al., 2010). Alumina $\left(\mathrm{Al}_{2} \mathrm{O}_{3}\right) \mathrm{NP}$ are used for making cutting tools and are often included as polishing agents just like ceria $\left(\mathrm{CeO}_{2}\right)$ 
NP (Cain and Morrell, 2001). Silica $\left(\mathrm{SiO}_{2}\right)$ NP have also been incorporated in insulating ceramics due to their coolant, light transmission and fire-resistant properties in the materials (Lee et al., 2010). On the other hand, nano-sized clays have been used as catalysis, in perforation, nanocomposites and inks (Wakamatsu and Salomao, 2010). Over the last years, great attention has been given to ceramic nanocomposites due to their capacity to improve mechanical, thermal and electrical properties comparing with the conventional ceramic matrix composites (Palmero, 2015; Rathod et al., 2017). Ceramic oxides such as $\mathrm{Al}_{2} \mathrm{O}_{3}, \mathrm{ZrO}_{2}, \mathrm{TiO}_{2}, \mathrm{Cr}_{2} \mathrm{O}_{3}$ and $\mathrm{SiO}_{2}$ are widely used as surface coating materials due to their capacity to improve resistance to wear, erosion, cavitation, fretting and corrosion (Knuuttila et al., 1998; Wang et al., 2009). Several processes for ceramics coating can be employed, for instance glazing, spraying, inkjet printing, laser-based processes and deposition techniques. These techniques often involve the injection of nanopowders that may lead to release and deposition of coarse and fine particulate matter (PM) (Fonseca et al., 2015a; Viana et al., 2017).

During the ceramic manufacturing process, the raw materials used can go through various transformation stages (Figure 1), that may pose different risks from the environmental point of view (Monfort et al., 2014). For instance, air emissions in the ceramic industry represent a major environmental concern due to the release of PM or dust during handling and processing of raw materials, as well as from gaseous compounds released during drying, calcination and firing of the raw materials (Barros et al., 2007; Bozsin, 1974). On the other hand, water emissions arise especially from manufacture of traditional ceramics and the resulting wastewater may contain insoluble PM, inorganic or organic materials and, in some cases, heavy metals (European Commission, 2007).

The development and exponential growth of nanotechnology-based industries, with an estimation of 6 million workers in 2020 (Roco, 2011), has raised concerns in the potential health risks of exposure to engineered (ENP) or airborne nanoparticles (ANP) (Woskie, 2010). Indeed, over the last years, NP have been regarded as emerging occupational hazards (Dolez and Debia, 2015). Yet, no official estimate of the number of workers involved in the use and manipulation of NP in the ceramic industry is currently available. This industrial sector is a relevant case of ENP and airborne particle exposure due to the increased likelihood of personal exposure to potentially hazardous materials during processing of raw materials and product manufacturing, where a wide range of nano- and bulk materials are used (Salmatonidis et al., 2019b).

The identification and characterization of NP exposure scenarios dictates the first stage of the workplace exposure assessment to these substances (Seipenbusch et al., 2014). The risk of occupational exposure to ANP strongly depends on its emissions levels, dispersion into the work environment and its eventual transformation within emission and exposure (Maynard and Kuempel, 2005). So far, it has not yet been possible to comprehensively assess the toxicity and establish the hazard of ENP and ANP, in particular, those derived from industrial ceramic 
processes. Nevertheless, there are several studies in the literature evidencing adverse effects of ANP exposure on human health in occupational settings. In fact, both airborne ultrafine particles (UFP; $<100 \mathrm{~nm}$ ) and NP have been associated with cardiopulmonary health effects through a series of key biological mechanisms (Stone et al., 2017).

This review provides a broad overview of the current knowledge on the workplace exposure to ENP and ANP in the ceramic industry and their potential adverse effects to the human health. Thus, this paper outlines possible NP sources and exposure scenarios in ceramic industrial settings, illustrated by a group of published case studies. A summary description of the existing methods for ANP's workplace exposure measurement, as well as the current legislation, i.e. occupational exposure limits (OEL) and existing Nano Reference Values (NRV), will also be provided and discussed. The present work will also bring together the current knowledge of the biological and adverse health effects from exposure to some NP, in particular those that are used as input materials and/or are representative of chemical elements found in the ceramic occupational setting. The literature search was conducted across two electronic databases: NCBI (Pubmed) and Science Direct. Gray literature was identified using internet-wide search engines (Google and Google Scholar). The following search terms were used: occupational health, occupational exposure, nanoparticles emissions, ultrafine particles emissions, ceramic, industrial settings and indoor air.

\section{Nanomaterials in the context of the ceramic industry}

\subsection{Occupational exposure to airborne nanoparticles}

\subsubsection{Sources and possible exposure scenarios}

Occupational exposure to NP can occur from a number of different sources including: (1) production/synthesis, (2) handling/transport, (3) use/application, (4) fracturing and abrasion and (5) waste recycling/disposal (Schneider et al., 2011). The risk of aerosol particle exposure is dependent on the type of source, rate of particle transport and its removal or accumulation in the work environment, which is greatly influenced by factors such as indoor and outdoor activities, ventilation system, room design, among others (Hämeri et al., 2009; Salmatonidis et al., 2019b). The most common scenarios of aerosol NP emissions at industrial workplaces are often associated with mechanical (e.g. high-energy drilling) and combustion/heating processes (e.g. firing), thermal coating techniques (e.g. thermal spray coating), flame-based powder generation and indoor air quality-related aerosols (e.g. office machinery, cleaning fluids, infiltration of ambient nanoaerosols) (Hämeri et al., 2009). Additionally, the use of nanopowders as input materials is obviously a risk factor for the presence of ANP in the workplace air. In this context, exposure scenarios related to the manufacture and use of fullerenes, CNT, metal and metal oxide NP have been already identified and reported by Aitken et al. (2004). 
Inhalation is considered the predominant route of exposure to ANP in occupational settings. However, ingestion and skin absorption exposure are also possible routes for NP during the manufacturing, use and disposal (Oberdorster et al., 2005). The smaller the particles the deeper they can penetrate into the lung (Heal et al., 2012; Oberdörster, 2000), eventually reaching the bloodstream and translocating to other organs (Fröhlich and Salar-Behzadi, 2014; Magdolenova et al., 2012; Vallyathan and Gwinn, 2006). Due to the high potential for fine and UFP release associated with the input materials and processes employed in ceramic industries, workers are likely exposed to these agents, which raise concerns on worker's health related to the poor indoor air quality (Aitken et al., 2004; Hristozov and Malsch, 2009).

At present, few studies on NP exposure in the ceramic industry exist. Most of ceramic raw materials are in the powder form. Therefore, when processing these materials, particularly in handling, transport, storage and mechanical treatment operations, fine particulate suspensions are generated in the air (Monfort et al., 2006). Moreover, high-energy processes such as laser ablation (LA), laser sintering (LS), physical vapour deposition (PVD), inkjet printing, plasma thermal spraying and glazing have a high potential for airborne particle formation and release to the workplace air (Fonseca et al., 2016; Fonseca et al., 2015b; Salmatonidis et al., 2019a; Salmatonidis et al., 2018; Viana et al., 2017). Machining processes (e.g. cutting, drilling, grinding) also possess a great potential for ANP release to the workplace environment as illustrated by manufacture of functionally graded materials by friction stir processing to produce aluminium (Al) alloys reinforced with $\mathrm{SiC}$ particles (Gandra et al., 2011). Fire and combustion processes are also highly associated with dispersion of combustible NP in the air, representing a greater risk (Hodson et al., 2009). For instance, NP containing metal oxide such as Al, cadmium $(\mathrm{Cd})$, chromium $(\mathrm{Cr})$, and copper $(\mathrm{Cu})$ have been associated with welding processes (Donaldson et al., 2005).

To sum up, the two major potential sources that may contribute to workplace exposure to ANP in the ceramic industry includes the use of nanopowders as input materials for ceramics production and airborne, process-generated NP released during the manufacture of ceramics as the result of the employed industrial processes and equipment (Figure 2). Due to the limited information on the ANP occupational exposure, these materials cannot be considered safe without thorough investigation regarding their exposure levels and toxicity, which is a current research gap. In the section 2.1.3. will be explained in detail the available studies found in the literature regarding ANP occupational exposure in the ceramic industry.

\subsubsection{Methods for workplace exposure evaluation}

To identify and characterize workplace exposure scenarios, two approaches can be adopted: studies at real workplaces or laboratory simulations of workplaces/work processes. The advantage of the first approach is to obtain data under real work conditions, however, is a time-consuming 
approach due to the numerous background aerosols. On the other hand, simulated workplace environments allow a clear differentiation of the aerosol's source, i.e. between background or particles unintentionally produced during the manufacturing process (Kuhlbusch et al., 2011). Measurement of worker's exposure to ANP can be performed using traditional industrial hygiene approaches that include: i) static (area) sampling, where samplers are placed at the source location, and ii) personal sampling, where samplers are fixed in the worker's breathing zone (Hodson et al., 2009). Accordingly, the available instrumentation for ANP exposure assessment can be divided into stationary, portable and personal (Table 2). Stationary equipment is the most accurate, however it only gives information at a single location at time. On the other hand, portable equipment, though easy to transport has lower accuracy and particle size resolution than the stationary equipment. In turn, personal equipment allows to monitor exposure levels in worker's breathing zone and are small and lightweight enough to be carried over an eight-hour shift, without compromising any activity carried out by the worker (Asbach et al., 2017; Tsai et al., 2012). Generally, personal sampling is considered the preferred method since it provides an accurate representation of the worker's exposure regarding inhalable, thoracic or respirable particle fractions (Stebounova et al., 2018). Table 2 presents a general overview of the existing methods and available instrumentation for ANP quantification. Time-resolving instruments (direct-reading) allow real-time determinations of parameters such as particle number concentration, particle size distribution or lung deposited surface area (LDSA) concentration, while time-integrating equipments are used for sampling material onto substrates and filters for posterior analysis on particle chemical composition and/or morphology (Kuhlbusch et al., 2011; O'Shaughnessy, 2013). The main drawback of direct-reading measurements is the limited instrument sensitivity to detect small particles (Asbach et al., 2017; Todea et al., 2015). Thus, the type of assessment (ambient $v s$ worker-oriented monitoring) and equipment used will greatly condition parameters to be assessed and quality of the obtained data. However, regardless the selected method for exposure monitoring, sampling conditions (start time, duration and frequency) are also critical for an accurate and reliable assessment of workers exposure. Furthermore, exposure measurements must take place before and during production and/or processing in order to understand the variation between ANP background levels and those found during the manufacturing activities (Hodson et al., 2009).

Despite exposure and air quality standards for particles being based on mass, when it comes to ANP or UFP, mass might not be the most meaningful metric due to the poor accuracy for measuring low mass concentrations in comparison with coarser particles (Oberdörster, 2010). At the same time, there is also an ongoing debate around NP dose metrics to be used in toxicological studies (Oberdörster et al., 2005; Oberdörster et al., 2007; Paur et al., 2011; Riediker et al., 2019; Wittmaack, 2006; Wittmaack, 2007). Features such as surface area, morphology and chemical composition have been found to play a relevant role in the responses to inhaled UFP and ANP 
(Oberdörster et al., 2005; Stone et al., 2017). While some hold the view that NP-induced effects seem to be more strongly associated with size than mass (Oberdörster, 2010; Singh, 2015), other authors postulate that depending on NP physicochemical features and mode of action, particle surface area might be the most biologically-relevant metric (Schmid and Stoeger, 2016). At present, there is no available instrument capable of measuring the ANP surface area. However, LDSA concentration is a surface-area related parameter that can be determined that corresponds to the fraction of the airborne particle surface area concentration deposited in the lung (Todea et al., 2015) that is more easily measured than total surface area (Geiss et al., 2016). The particle lung deposition estimated by LDSA is an important aspect to take into consideration in occupational assessment, being influenced by parameters such as particle size, surface chemistry, distribution, breathing pattern and lung morphology rather than particle mass concentration (Reche et al., 2015).

Measurement of workplace exposure is thus essential to identify ANP sources and exposure levels, to implement control measures to efficiently reduce the exposure, contributing for the prevention of potential risks for worker's health. In this regard, mathematical/computational modelling can also be helpful to estimate exposure assessment through the analysis of the transport and fate of particles within the workplace environment (Schneider et al., 2011). Control banding $(\mathrm{CB})$ is also of interest to manage workplace risks associated with occupational exposure to NM. Considering NM particularities, specific CB tools for NM have been developed (e.g. Stoffenmanager Nano, Nanosafer, CB Nanotool), with exposure assessments and derived risk levels (bands) based on different concepts and assumptions, and outputs in different formats (Liguori et al., 2016; Schulte et al., 2010; van Broekhuizen et al., 2012a).

\subsubsection{Occupational exposure limits (OEL)}

Occupational exposure limits (OEL) aim to protect from levels of exposure to airborne chemicals and particles that may endanger human health (Schenk and Johanson, 2010; Schulte et al., 2010). These are mostly derived from extrapolation of animal data to human, with all the related uncertainties and limitations of this estimate. A common procedure towards the definition of OEL in case of uncertain and insufficient data is the use of uncertainty factors (Schenk and Johanson, 2010). Currently, no official OEL for NP have been establish by any regulatory agency (Mihalache et al., 2017), mostly due to the uncertainty of ANP impact on human health (van Broekhuizen et al., 2012b). Notwithstanding, some organizations have provided guidance on benchmark levels. The Dutch Social and Economic Council has proposed Nano Reference Values (NRV) as a provisional substitute for OEL (Table 3) and preventive measures to control exposure to NP in the workplace environment. NRV are calculated based on the background-corrected number of NP with the diameter of $100 \mathrm{~nm}$ and a mass of $0.1 \mathrm{mg} / \mathrm{m}^{3}$ (Mihalache et al., 2017) and not derived from any toxicological and epidemiological data. Accordingly, they constitute a 
precautionary risk management tool for NM handling or processing in the workplace, but they do not guarantee that exposures below those values are safe as they are built on presumable health effects (van Broekhuizen et al., 2012a).

Pietroiusti and colleagues have compiled a number of proposed OEL for several ENP recommended by different institutions worldwide (Pietroiusti and Magrini, 2014; Pietroiusti, 2018). The World Health Organization (WHO) has also released guidance on protection of workers health from manufactured NP exposure based on the existing evidence of NP effects on human health, where a list of proposed OEL is also presented (World Health Organization, 2017). Altogether, these compilations demonstrate the efforts and progresses made over the past years to establish and define concrete and coherent OEL for NP. Nevertheless, there is still much work ahead, particularly in defining ANP-derived OEL in the context of industrial activities such as in the ceramic sector. The ongoing discussions on the metrics to be used for future "nano-OEL", i.e. mass-based or particle number-based, is also making difficult their successful implementation. While mass-based OEL are suitable for bulk materials, values for materials at the nanoscale seem to be rather high (Schulte et al., 2010). An additional limitation for the creation of nano-OEL is that NM are usually measured as primary NP and these are frequently presented in the workplace environments as micro-sized agglomerates, which may impar the correct classification for these OEL (Mihalache et al., 2017).

\subsection{Airborne nanoparticle release and exposure in the ceramic industry: case} studies

Just in recent years, studies on workplace exposure to ANP in ceramic industry settings began to emerge in the literature. This chapter focus on the existing case studies of ultrafine and ANP emissions during different stages of the ceramic manufacturing process, which are summarized in Table 4.

\subsubsection{Firing process}

The pioneering work of Voliotis et al. (2014) investigated the size, concentration and elemental composition of particles emitted during the different stages of the ceramic firing process, i.e. before and after ceramics painting and glazing, in a traditional small-sized pottery studio. This study showed that when the kiln reached temperatures above $600^{\circ} \mathrm{C}$ most of the emitted particles were in the nanometer range. The size of the emitted ANP varied between 30-70 nm during the first stage of the firing process, where the ceramics were unpainted and unglazed, with a peak concentration around $6.5 \times 10^{5}$ particles $/ \mathrm{cm}^{3}$. In the second stage of the firing process, where the ceramics were painted and glazed, the mean particle size ranged from 15 to $40 \mathrm{~nm}$ and their particle number concentration peaked at $1.2 \times 10^{6} / \mathrm{cm}^{3}$. Elemental analysis by Energy-Dispersive $\mathrm{X}$-ray (EDX) spectroscopy of individual particles collected during the two firing stages revealed 
that the main element found was $\mathrm{Si}$, emitted by the clay, whereas the second firing stage mostly generated particles containing $\mathrm{Pb}$ and $\mathrm{Cu}$ derived from the pigments used for glazing (Voliotis et al., 2014).

\subsubsection{Surface treatment processes}

In the ceramic industry, the use of laser-based techniques to improve ceramics surface properties is becoming widespread. The high-energy nature of these lasers may entail some risks of NP generation and emission. Fonseca and co-workers have investigated particle emissions during two processes using laser technology, laser sintering (LS) and laser ablation (LA) of ceramic tiles. In the first study, particle measurements were performed at laboratory scale both at the emission source, a three meters long pilot plant-scale furnace, and at the worker's breathing zone (Fonseca et al., 2015b). ANP emissions were found to be highly dependent on temperature and tile chemical composition and induced by thermal and nucleation processes. Primary ANP emissions with a particle mean diameter of $18 \mathrm{~nm}$ reached concentrations up to $6.7 \times 10^{6}$ particles $/ \mathrm{cm}^{3}$. In the indoor area (breathing zone), particles decreased in number, mass and LDSA concentration but they were still present at high concentrations and in a size range of 13 to $27 \mathrm{~nm}$. In the workers' breathing zone, the collected particles presented diameters larger than in the furnace but smaller than the background air. The highest concentrations of metals including $\mathrm{Zn}, \mathrm{Pb}, \mathrm{Cu}, \mathrm{Cr}$, As and Ti have been found in the UFP fraction (Fonseca et al., 2015b). In a second study, the authors addressed ANP formation and release mechanisms from tile sintering using high power $\mathrm{CO}_{2}$ lasers but at industrial scale in a seven meters long industrial furnace (Fonseca et al., 2016). They have underlined the difficulty to directly extrapolate particle emissions obtained at laboratory scale to industrial scale due to three main reasons: (1) Fuel: laboratory furnaces are electric, while industrial furnaces are gas-powered; (2) Gas flow: inside industrial furnaces it is much higher than in laboratory furnaces; and (3) Area: a larger working area is expected in industrial than in laboratory settings resulting in a higher particle dispersion and consequently lower particle concentrations in the breathing zone. According to this workplace exposure evaluation, new particle formation from gaseous precursors occurred during thermal treatments in both red clay and porcelain ceramic materials. This phenomenon was independent of the laser treatment. Generation and emission of ultrafine and nano-sized airborne particles occurred during the sintering process of the ceramic facility under study, and the measured exposure concentrations exceeded NRV (Fonseca et al., 2016).

Salmatonidis et al. (2018) investigated the mechanisms behind ANP formation and emission during pulsed LA of four types of ceramic tiles, using two different laser setups: near-infrared laser widely used for engraving, and mid-infrared laser generally employed for cutting and welding. These authors considered the influence of the ceramic material properties, process parameters and lasers wavelength on the formation and release of ANP, characterizing them in 
terms of size, particle number and mass concentration both at laboratory and pilot-plant-scale. Regardless the laser wavelength used and type of ceramic tile, a high particle number concentration of ANP, from $3.5 \times 10^{4} / \mathrm{cm}^{3}$ to $2.5 \times 10^{6} / \mathrm{cm}^{3}$ was released. Particles of $\mathrm{SiO}_{2}$ and $\mathrm{Al}_{2} \mathrm{O}_{3}$ with sizes superior to $10 \mathrm{~nm}$ were formed and released during the LA process of the ceramic tiles. ANP emissions were associated with different mechanisms including nucleation and melting, which highly contributed to the particle number concentration observed. In addition, the ceramic surface and chemical properties exerted a great effect on the particle number and mass emissions of ANP (Salmatonidis et al., 2018).

Viana et al. (2017) evaluated airborne UFP $(<100 \mathrm{~nm})$ and NP $(<50 \mathrm{~nm})$ emissions during atmospheric plasma spraying (APS) of ceramic coatings at industrial-scale pilot level. Plasma spraying was performed inside a closed chamber located inside the worker's room, where the breathing zone was $1.5 \mathrm{~m}$ away. Particle size ranged between 10 and $700 \mathrm{~nm}$ and ultrafine emissions were higher than initial background concentrations, reaching up to $3.7 \times 10^{6}$ particles $/ \mathrm{cm}^{3}$ and $2.0 \times 10^{6} / \mathrm{cm}^{3}$ inside the spraying chamber and at workers' area, respectively. These results demonstrate the hazardous potential of these airborne particles in ceramic industrial environments. In this study, it has also been applied a risk prevention protocol consisting of (1) improved air circulation in the plasma chamber and delayed door-opening system, (2) improvement of the sealing of the extraction system ducts and (3) air exchange rates (forced ventilation in the worker area). These measures proved to be effective in reducing UFP concentrations in the workers area (Viana et al., 2017).

Recently, Salmatonidis and colleagues have evaluated particle emission and its impact on worker's exposure during thermal spraying of ceramic coatings onto metallic surfaces (Salmatonidis et al., 2019a). Several parameters were analysed including particle number and mass concentrations, LDSA, mean diameter, and size distributions of NP, fine and coarse particles. Inside the thermal spraying booths, high particle number $\left(>10^{6} / \mathrm{cm}^{3}\right)$ and mass concentrations (60-600 $\left.\mu \mathrm{g} \mathrm{PM}_{1} / \mathrm{m}^{3}\right)$ have been detected. Those particles were transported towards the worker area, increasing the concentrations in this region by one order of magnitude in terms of number $\left(10^{4}-10^{5}\right.$ particles $\left./ \mathrm{cm}^{3}\right)$, and up to a factor of 4 in terms of mass $(44-100 \mu \mathrm{g} \mathrm{PM}<$ $1 \mu \mathrm{m} / \mathrm{m}^{3}$ ) contributing for the potential worker's exposure to these particles (Salmatonidis et al., 2019a). Characterization of the emitted ANP found at the workers area revealed that they were irregularly-shaped, mostly between $26-90 \mathrm{~nm}$ and constituted by metals such as nickel (Ni), $\mathrm{Cr}$ and tungsten (W). ANP generation and emission were mainly associated with mechanical attrition, but also melting-evaporation-condensation of the feedstock materials. Inhaled dose rates ranged from $353 \times 10^{6}-1024 \times 10^{6}$ particles $/ \mathrm{min}$, where $70 \%$ of particle deposition was estimated to occur in the alveolar region (Salmatonidis et al., 2019a).

\subsubsection{Handling and packaging of ceramic materials}


Ribalta et al. evaluated the workers personal exposure to airborne particles during handling of five highly used ceramic materials with different characteristics (silica sand, three types of quartz and kaolin), as well as material dustiness, at pilot-plant-scale (Ribalta et al., 2019a). Dustiness measures the predisposition of a material to generate airborne dust during the handling and constitutes a relevant parameter to be taken into account in the context of ANP exposure evaluation in occupational settings. In this study, several parameters were evaluated including particle mass, number concentration, LDSA and particle size distribution. All ceramic materials under study presented a great impact on workers exposure regarding inhalable and respirable mass and images of Transmission Electron Microscopy (TEM) supported the presence of ANP in the form of aggregates $(300 \mathrm{~nm}-1 \mu \mathrm{m})$. In terms of mean inhalable mass concentrations, higher levels were consistently found during materials handling under high-energy settings compared to background levels. Nonetheless, in terms of particle number concentrations, no major differences were found before (background levels) and during materials handling. Moreover, a correlation between exposure concentration and dustiness has been demonstrated under the conditions and materials used, strengthening the idea that dustiness is a relevant parameter for the prediction of worker exposure (Ribalta et al., 2019a).

Ribalta et al. have also investigated the effectiveness of source enclosure in particle release during packaging of ceramic raw materials (Ribalta et al., 2019b). Worker's exposure was monitored during the packaging process of seven ceramic materials in three packaging lines equipped with different levels of source containment: low (L), medium (M) and high $(\mathrm{H})$. As expected, real-time measurements showed that packaging lines $\mathrm{L}$ and $\mathrm{M}$ significantly increased exposure concentrations, while non-significant increases were detected in line H. These findings demonstrated the effectiveness of source enclosure as a mitigation strategy in the case of packaging of ceramic materials. The ICRP human respiratory tract model revealed that particle deposition occurred mainly in the alveoli (51-64\%) followed by head airways (27-41\%) and trachea bronchi (7-10\%). In this study, different risk assessment tools (Stoffenmanager, ART, NanoSafer) were also employed to test the effectiveness of source containment. The comparison between the results from different risk assessment tools and the measured exposure concentrations evidenced that all of the tools overestimated exposure concentrations, by factors of $1.5-8$. These findings underline the limitations of the available risk assessment tools to predict real scenario exposure levels and the urgent need to improve them.

\subsubsection{General remarks}

All of the aforementioned case studies evidence the relevance of studying fine, ultrafine and ANP process-generated emissions in ceramic workplaces and their impact on worker air exposure. Even though the number of workers in each of the case studies is not especially high (ranging approximately between 2 and 10 workers/activity) (Salmatonidis et al., 2019b; Viana et al., 2017; 
Voliotis et al., 2014), there are two main factors supporting the relevance of these exposures: (1) the fact that particles are rapidly transported across the industrial facilities (Ribalta et al., 2019b), impacting workers active in other tasks different from the ones assessed in the case studies, and therefore not wearing any personal protective equipment (PPE), and (2) the increasing number and type of activities during which process-generated NP are being identified (see the recent case studies above), which indicates that this type of particles may be more frequent in industrial scenarios than previously thought. Overall, the reported observations and findings emphasize the importance of the risk assessment and the implementation of prevention procedures to improve occupational air quality in ceramic industrial settings.

\section{Human health effects of exposure to intentional and unintentional nanoparticles in the ceramic industry: what do we know so far?}

In spite of the great number of studies addressing the issue of NP toxicity, many challenges remain to identify the health impact of exposure to these materials. In fact, inconsistent and often conflicting data regarding the safety of NP are found in the literature. Consequently, relatively little is known about their effects on human health. Despite their distinct origins, NM and UFP share many similarities in terms of their physicochemical properties and in vitro mode of action (MoA) (Stone et al., 2017). Accumulating evidence shows that exposure to ambient air PM is associated with negative health outcomes and nano-sized (ultrafine) particles are likely to play an important role. The lung is a main target for inhaled NP though they may also translocate into the bloodstream triggering nonspecific interactions with secondary organs and systemic tissues (Oberdörster et al., 2005). Indeed, exposure to nano-sized particles has been widely associated with impaired lung function and inflammation, vascular dysfunction and adverse acute respiratory and cardiovascular effects (Stone et al., 2017). In turn, these adverse effects are strongly linked with different diseases such as lung cancer (Knaapen et al., 2004), bronchitis, acute asthma (Kreyling et al., 2006), cardiac infection, hypertension, atherosclerosis, ischemia and cardiac arrhythmia (Brook et al., 2004; Kelly and Fussell, 2015; Schulz et al., 2005; Shannahan et al., 2012), among others. In the context of the ceramic industry, many reports show that occupational exposure to ceramic dusts and fibres is associated with chronic bronchitis, chronic obstructive pulmonary disease, reduced lung function, wheezing, breathlessness and dry cough (Jaakkola et al., 2011; Kargar et al., 2013; Trethowan et al., 1995).

From the in vitro and in vivo studies conducted so far, NP mechanisms of action start to be unravelled. Major mechanisms involved in NP-induced pulmonary toxicity events already described in the literature include: (1) ineffective clearance of NP; (2) intracellular uptake/internalization of NP; (3) impairment of lung macrophage phagocytosis; 4) loss of plasma membrane integrity; (5) mitochondrial dysfunction; (6) oxidative stress (ROS generation, glutathione depletion, lipid peroxidation); (7) cytokine production and activation of inflammatory 
signalling cascades; (8) genotoxicity (DNA and chromosomal damage, altered DNA methylation and repair); (9) altered cell cycle regulation, among others (Bakand et al., 2012; Li et al., 2010; Paur et al., 2011; Pietroiusti et al., 2018 ; Stone et al., 2017).

Singh et al. reviewed several aspects related to cellular uptake and possible toxicity mechanisms of ceramic NP for drug delivery applications. In this paper, aspects related to the mechanisms of NP internalization, possibly through passive uptake or simple adhesive interactions, accumulation in phagosomes, pattern of subcellular distribution (e.g. cytoplasm, mitochondria, lipid vesicles or nucleus) and its relation to observed adverse biological outcomes (e.g. organelle and genetic material damage, cell death) are discussed (Singh et al., 2016).

Over the years, more and more NM have been introduced in the ceramic industry. At the same time, as previously described, NP emissions can arise from multiple processes employed in the ceramic industry that neither produce nor use NM, which are referred as process-generated nanoparticles (PGNP). Below, a major overview of the existing in vitro and in vivo pulmonary toxicology studies of representative ENP and PGNP found in ceramic occupational settings (described in section 2.2) will be presented.

Clays are one of the most common materials applied in the ceramic sector. Lately, there has been a wide implementation of nano-sized clays in the industry, which raises concerns for the potential risks of these NM for the exposed workers health. In vitro studies have shown that nanoclays exposure (e.g. montmorillonite) decreases cell viability and induces changes in morphology and cell-cell interactions in human lung epithelial cells (Wagner et al., 2017a; Wagner et al., 2017b; Wagner et al., 2018). Stueckle et al. also evaluated the effects of pre- and post-incinerated forms of uncoated and organomodified nanoclays in mice and observed that pulmonary inflammation and toxicity relies on coating presence and incineration status. The obtained data revealed that coated and incinerated nanoclays induced less inflammation and granuloma formation in mice than pristine montmorillonite (Stueckle et al., 2018).

Metals and metal oxides NP are also commonly utilized in the ceramic industry. Brunner et al. (2006) evaluated the toxicity of $\mathrm{CeO}_{2}, \mathrm{TiO}_{2}, \mathrm{ZrO}_{2}$ and $\mathrm{ZnO} \mathrm{NP}$ in human lung mesothelioma (MSTO) exposed to 0-30 ppm for 3- and 6-days. Among the tested NP, ZnO NP were the most cytotoxic, while $\mathrm{CeO}_{2}, \mathrm{ZrO}_{2}$ and $\mathrm{TiO}_{2} \mathrm{NP}$ induced analogous responses in MSTO cells. Similar findings were observed by Xia et al. that have compared the effects of $\mathrm{ZnO}$ and $\mathrm{CeO}_{2} \mathrm{NP}$ in human bronchial epithelial cells (BEAS-2B). These authors found that ZnO NP induced greater cytotoxicity and cell death through generation of ROS and induction of inflammation than $\mathrm{CeO}_{2}$ NP, whose exposure suppressed ROS production and induced resistance to an exogenous source of oxidative stress in BEAS-2B cells (Xia et al., 2008). Lanone et al. have also comparatively assessed the toxicity of $\mathrm{Al}_{2} \mathrm{O}_{3}, \mathrm{CeO}_{2}, \mathrm{TiO}_{2}, \mathrm{ZrO}_{2}, \mathrm{CuO}$ and $\mathrm{ZnO} \mathrm{NP}$ up to $5000 \mu \mathrm{g} / \mathrm{mL}$ at $24 \mathrm{~h}$ after exposure in human alveolar epithelial (A549) and macrophage (THP-1) cell lines. While exposure to $\mathrm{Al}_{2} \mathrm{O}_{3}, \mathrm{CeO}_{2}, \mathrm{TiO}_{2}$ and $\mathrm{ZrO}_{2} \mathrm{NP}$ caused a moderate toxicity in both cell lines, 
incubation with $\mathrm{CuO}$ and $\mathrm{ZnO}$ NP markedly decreased cell viability of A549 and THP-1 cells (Lanone et al., 2009). Moreover, Kim et al. also evaluated $\mathrm{Al}_{2} \mathrm{O}_{3}, \mathrm{CeO}_{2}, \mathrm{TiO}_{2}$ and $\mathrm{ZnO} \mathrm{NP}$ cytotoxicity to human lung cells and found out that $\mathrm{ZnO} \mathrm{NP}$ were the most cytotoxic with regard to cell proliferation, viability, membrane integrity and colony formation endpoints. On the other hand, $\mathrm{Al}_{2} \mathrm{O}_{3}, \mathrm{CeO}_{2}$ and $\mathrm{TiO}_{2} \mathrm{NP}$ did not significantly affect cell proliferation and viability, being $\mathrm{Al}_{2} \mathrm{O}_{3} \mathrm{NP}$ the least toxic NP tested (Kim et al., 2010).

Regarding the $\mathrm{CeO}_{2} \mathrm{NP}$, there is some controversy around its toxicological potential in pulmonary cell models. While some studies have demonstrated that exposure to $\mathrm{CeO}_{2} \mathrm{NP}$ decrease cell viability, induce oxidative stress (Eom and Choi, 2009a; Lin et al., 2006b; Park et al., 2008b) and affect DNA integrity (De Marzi et al., 2013) of human lung epithelial cells, others reported no signs of cytotoxicity following exposure to these NP (Park et al., 2008a; Rothen-Rutishauser B, 2009).

Monocultures are a convenient but a rather simplified model that can be less sensitive to predict toxicity than more advanced cell culture models. Three-dimensional (3D) cultures with a fully differentiated epithelium, more than one cell type, and with a morphology and genome wide expression similar to that observed in vivo have been shown to closely mimic human exposure to aerosolized NP (Clippinger et al., 2016), offering a good alternative to in vivo testing. In addition, lung cell models grown and exposed to aerosols at the air-liquid interface (ALI) are increasingly being recognized as a more realistic system to address the toxicity of inhaled agents compared to the classical submerged exposures (Lacroix et al., 2018). In this regard, Kupper et al. investigated the toxicity of $\mathrm{CeO}_{2} \mathrm{NP}$ in human lung epithelial A549 and BEAS-2B cell lines under submerged conditions but also in $3 \mathrm{D}$ cultures of human bronchial epithelium (MucilAir ${ }^{\mathrm{TM}}$ cultures) at ALI conditions. The obtained results showed that $\mathrm{CeO}_{2} \mathrm{NP}$ did not induce cytotoxicity, as assessed by the LDH release assay, but caused a concentration-dependent increase in DNA damage levels in BEAS-2B exposed cells, while exposure of A549 cells to $\mathrm{CeO}_{2} \mathrm{NP}$ induced a minimal increase in LDH and a distinct increase in DNA damage. On the other hand, none of these responses were observed in MucilAir ${ }^{\mathrm{TM}}$-exposed cells, where minimal translocation of $\mathrm{CeO}_{2} \mathrm{NP}$ across the 3D barrier was detected (Kuper et al., 2015). The mucociliary clearance appeared to prevent aerosolized $\mathrm{CeO}_{2} \mathrm{NP}$ to reach the respiratory epithelial cells in the $3 \mathrm{D}$ airway cultures. Nevertheless, toxic responses such as cytotoxicity (e.g. loss of viability and plasma membrane integrity), inflammation responses, recruitment of alveolar macrophages and neutrophils were observed in vivo, in the lung tissue of rats exposed to $\mathrm{CeO}_{2} \mathrm{NP}$ by intratracheal instillation (Ma et al., 2011), nose-only (Srinivas et al., 2011) and whole-body inhalation (Keller et al., 2014) to $\mathrm{CeO}_{2} \mathrm{NP}$.

$\mathrm{TiO}_{2} \mathrm{NP}$ are widely used in the industry and consumer products worldwide due to their high stability, anticorrosive and photocatalytic properties (Shi et al., 2013). Still, the International Agency for Research on Cancer (IARC) has classified bulk $\mathrm{TiO}_{2}$ as possibly carcinogenic to 
humans (group 2B) (Baan, 2007), which raised concerns about the genotoxic potential of $\mathrm{TiO}_{2}$ in the nanoform. At present, the toxicological potential of $\mathrm{TiO}_{2} \mathrm{NP}$ is controversial. According to the previously mentioned in vitro cytotoxicity studies, $\mathrm{TiO}_{2} \mathrm{NP}$ seem to moderately affect lung cell lines. However, several in vitro studies have shown that $\mathrm{TiO}_{2} \mathrm{NP}$ can cause DNA damage and impair DNA repair mechanisms in lung cells. In this regard, Biola-Clier et al. compared the response of bronchial (BEAS-2B) and alveolar (A549) epithelial cells upon exposure to 1-100 $\mu \mathrm{g} / \mathrm{mL}$ of $\mathrm{TiO}_{2} \mathrm{NP}$ in terms of DNA integrity. Both cell lines exhibited similar responses, i.e., moderate cell death, oxidative DNA damage and impaired DNA repair. So far, no consistent in vivo genotoxic profile has been established for $\mathrm{TiO}_{2} \mathrm{NP}$, with the route of exposure and dose influencing the genotoxic outcome (Chuang et al., 2014). Several in vivo inhalation and instillation studies showed negative genotoxicity outcomes for $\mathrm{TiO}_{2}$ NP (Lindberg et al., 2012; Naya et al., 2012). At the same time, Relier et al. found that only under overload conditions (3 instillations of $10 \mathrm{mg} / \mathrm{kg}$ ) $\mathrm{TiO}_{2} \mathrm{NM}_{\mathrm{N}} 05$ (rutile-anatase) induced delayed genotoxicity in lung, associated with persistent inflammation (Relier et al., 2017). In fact, the lung inflammation is the most common adverse outcome derived from $\mathrm{TiO}_{2} \mathrm{NP}$ exposure (Noël and Truchon, 2015).

Silica $\left(\mathrm{SiO}_{2}\right)$ is one of the most common and well-studied occupational hazards (PoinenRughooputh et al., 2016). Occupational exposure to crystalline $\mathrm{SiO}_{2}$ is intimately related with the development of silicosis, a fibrotic lung disease (Leung et al., 2012). An increased risk of lung cancer has been found in groups exposed to high levels of respirable $\mathrm{SiO}_{2}$ such as miners and brick, diatomaceous earth, pottery, sand and stone workers. However, carcinogenicity of inhaled crystalline $\mathrm{SiO}_{2}$ has also been observed in a population with a wide variety of exposure circumstances, suggesting that the burden of cancer induced by $\mathrm{SiO}_{2}$ may be much greater than previously expected (Vida et al., 2010). Micro-sized $\mathrm{SiO}_{2}$ NP is widely used in the ceramic industry, but the use of nanosized $\mathrm{SiO}_{2}$ has potential to grow in the coming years. $\mathrm{SiO}_{2}$ toxicological potential was believed to be related with its crystallinity. Amorphous $\mathrm{SiO}_{2}$ has been considered less harmful than crystalline $\mathrm{SiO}_{2}$ (Murugadoss et al., 2017). Notwithstanding, most recent findings (Pavan et al., 2019; Pavan and Fubini, 2017; Turci et al., 2016) suggested that crystallinity per se cannot explain toxic effects of $\mathrm{SiO}_{2}$, which are more linked to surface chemistry, specifically to silanol disorganization. The comparison studies show that amorphous $\mathrm{SiO}_{2} \mathrm{NP}$ can induce similar acute toxicological activity compared to crystalline silica, but much less chronic effects (at 3-months), which can be attributed to its lower biopersistence (Arts et al., 2007). In vitro studies in lung cell lines have shown decreased cell viability, increased levels of oxidative stress (e.g. ROS production, lipid peroxidation) (Akhtar et al., 2010; Eom and Choi, 2009b; Lin et al., 2006a; McCarthy et al., 2012), induction of DNA damage (Decan et al., 2016; Maser et al., 2015) and inflammatory responses (Panas et al., 2014; Panas et al., 2013) following exposure to $\mathrm{SiO}_{2} \mathrm{NP}$. Most of the in vivo instillation and inhalation studies for amorphous $\mathrm{SiO}_{2}$ NP available in the literature reported induction of inflammatory responses (Cho et al., 2007; 
Guichard et al., 2015) but no genotoxic responses (Guichard et al., 2015; Maser et al., 2015; Sayes et al., 2010) though in vitro these NP seemed to present a high toxic potential.

Copper $(\mathrm{CuO})$ and nickel $(\mathrm{NiO})$ oxide $\mathrm{NP}$ can also be used in the ceramic industry incorporated in inks for surface coating treatments. There are several studies showing a marked toxicity effect of $\mathrm{CuO}$ NP in lung cells lines, most of them showing a decrease in cell viability, increased DNA damage and oxidative stress (Ahamed et al., 2010; Cronholm et al., 2013; Fahmy and Cormier, 2009; Ivask et al., 2015; Karlsson et al., 2008; Midander et al., 2009; Wang et al., 2012). In vivo, $\mathrm{CuO} \mathrm{NP}$ has been investigated in Wistar rats after short-term inhalation (STIS) exposure for 5 days/6h per day to doses up to $13.2 \mathrm{mg} / \mathrm{m}^{3}$ (Gosens et al., 2016). Twenty-four hours after the last exposure, a dose-dependent lung inflammation and cytotoxicity were observed. However, after a recovery period of 22 days, limited lung inflammation was only observed at the highest dose (Gosens et al., 2016). Cho et al. (2012) evaluated $\mathrm{CuO}$, $\mathrm{NiO}$ and $\mathrm{ZnO} \mathrm{NP}$ toxicity following intratracheal instillation in the rat. In this study, a severe pulmonary immune response with recruitment of eosinophils and neutrophils has been observed in rats exposed to the $\mathrm{CuO}$ and $\mathrm{ZnO}$ NP, while in NiO NP-exposed animals only neutrophils were recruited into the lung (Cho et al., 2012). Special attention should been given to NiO NP considering that Ni compounds are classified as carcinogenic to humans (International Agency for Research on Cancer, 2012; Mulware, 2013). Horie and his colleagues evaluated the cytotoxicity of ultrafine and fine $\mathrm{NiO}$ particles and observed that the UFP induced higher toxicity than the fine particles (Horie et al., 2009) and caused an acute oxidative stress response (Horie et al., 2011). Marked toxic responses including cell damage, induction of oxidative stress and activation of antioxidant systems in the lungs of rats intratracheally instilled with ultrafine $\mathrm{NiO}$ particles have also been reported by Horie et al. (2011), which are consistent with the marked toxic effects observed in vitro. Interestingly, a case report on occupational handling of a NiO NP powder by a 26 -year-old female described the occurrence of $\mathrm{Ni}$ sensitization caused by manipulation of the nanopowder without any respiratory protection or control measures (Journeay and Goldman, 2014). This case highlights the importance of the nanotoxicological studies, and the evaluation of adverse health effects associated with these materials, particularly at industrial settings, in order to develop precautionary measures to protect workers from NP exposure and help preventing these workrelated incidents.

As previously mentioned, graphene and CNT are used in the ceramic industry for their reinforcing ability. Previous toxicity studies on materials from the graphene family (e.g. graphene oxide, graphene nanosheets, among others) have shown that inhalation of these materials may potentially cause adverse biological responses. For instance, a decrease in cell viability and apoptosis in lung cells was already observed in vitro, while in animal studies, lung granuloma formation, inflammatory responses, pulmonary edema, severe and persistent lung injury were some of the effects caused from exposure to graphene family materials to rodents (Su et al., 2016). Regarding 
CNT, these are valuable industrial products. However, studies commonly suggest that human pulmonary exposure during production and manipulation might present pathogenic effects similar to asbestos fibers, due to their alike fibrous morphology (Donaldson et al., 2013; Shvedova et al., 2009). However, it is worth mentioning that depending on the diameter and rigidity of the CNT, they may present different toxicological mechanisms from asbestos. For instance, while asbestos are endocytosed by mesothelial cells regardless of their diameter, CNT are internalized in a diameter- and rigidity- dependent manner, preferentially smaller diameters and higher rigidity nanotubes, which may influence their toxicity on those cells (Nagai et al., 2011; Nagai and Toyokuni, 2012). Both in vitro and in vivo studies have shown that CNT induce oxidative stress, apoptosis in different cell lines and induce cytotoxic effects in the lung (Kayat et al., 2011). Also, in animal studies, CNT have shown to be highly biopersistent, being capable to induce pulmonary inflammation, fibrosis, lung cancer after long-term inhalation and gene damage in the lung (Kobayashi et al., 2017). However, Manke et al. (2014) suggests that additional research is needed to understand if the airborne CNT generated in workplace settings are comparable in terms of size and structure to the ones generated for the in vitro and in vivo studies.

Despite the great importance of in vitro and in vivo testing, care should be taken regarding the interpretation and extrapolation to humans, particularly in case of animal inhalation toxicology area, where the anatomical and physiological differences between laboratory animals and humans could result in distinct responses to the airborne and inhalable particles (Irvin and Bates, 2003; Ware, 2008 ). Though, these studies might give a major clue of the possible mechanisms of toxicity that may occur in humans after exposure to such particles and the associated harmful health effects.

Due to the increasing number of workers exposed to fine and nano-sized particles of different origins and sources, further studies must be carried out for toxicity and dose-response assessment of ANP deemed relevant in occupational settings, in particular for the ceramic industry. Therefore, identification of potential sources and characterization of airborne particles emissions in terms of emitted levels, chemical composition, size distribution, etc., is of utmost importance not only for the risk assessment of exposure to these particles but also to develop plans to prevent or reduce workers exposure, namely the establishment of OEL for ANP.

\section{Conclusions and future directions}

Several industries are benefiting from advances provided by nanotechnology-derived materials and innovative processes. Indeed, owing their unique physicochemical properties, the utilization of $\mathrm{NM}$ as input materials is widespread in the industrial field. At the same time, high-energy processes aimed to enable the rapid manufacture of high-quality, innovative and cost-competitive products may also generate incidental ANP, the so-called PGNP, meaning that these workers are a susceptible population to NP exposure. At present, there is some uncertainty around the true 
risk of NM to the environment and human health, which raises serious public health concerns. These concerns are further aggravated by the existing epidemiological evidence linking exposure to high ambient concentrations of PM to morbidity and mortality, for which the ultrafine particle fraction seems to be an important contributor.

The ceramic industry is a paradigmatic case of potential occupational exposure to airborne nanosized particles, mainly when high energy processes are implemented, as evidenced by the existing exposure monitoring data. Advances in the instrumentation used for ANP workplace measurements shed light on the possible exposure scenarios arising from ENP handling or from different ceramic industry activities (e.g. machining, firing, surface coating, packaging), many of them transversal to other industrial branches. This knowledge is crucial for an effective NM risk assessment and management, in particular for the implementation of risk prevention and mitigation measures for protecting workers from intentional or unintentional exposure to ANP but also for helping in the establishment of meaningful OEL for ANP. Therefore, more exposure assessment studies are needed, in particular in the ceramic industry, for a more extensive identification of workplace exposure scenarios and a more detailed characterization of the ANP found in terms of number, size, shape, aggregation/agglomeration, chemical composition and toxicological properties. In this context, CERASAFE (http://www.cerasafe.eu/) has been a pioneering European project that contributed to innovating in the field of characterization methods relevant to environmental health and safety (EHS) issues, namely to discriminate ENP from background aerosols in the ceramic industry and good practices to guarantee that exposure to hazardous NP may be acceptable.

In parallel with exposure assessment, is urgent to fill the gaps on the knowledge of the adverse health effects derived from ANP exposure and their relation to dose to move forward our understanding of the occupational hazard of ENP and ANP. Currently, no OEL specific to NM have been officially established and adopted by the authoritative agencies, on one hand due to the vast heterogeneity and number of available $\mathrm{NM}$, on the other to the limited and controversial knowledge of NM toxicity and harmful health effects. Furthermore, increasing evidence supports that the commonly used mass metrics for OEL may need to be carefully analysed and considered to be replaced by a particle number-based approach, a fact that has also been hampering the OEL developing process. Meanwhile, NRV may be considered as a provisional precautionary tool to protect the workers from NP exposure. Concerted efforts within the EU Nanosafety Cluster are being done in order to develop grouping and read-across approaches, similar to what is already well-established for conventional chemicals, that can be used to fill data gaps without further testing, with the ultimate goal of accelerating NM safety assessment and assisting in the establishment of OEL for specific NM groups. In this regard, several research projects (e.g. Gracious, NanoToxClass, PATROLS, SmartNanoTox) are contributing to NM categorization based on the joint consideration of NM physicochemical properties and modes of action. 
Inflammation, oxidative stress, genotoxicity are the most frequently reported responses to NM exposure as revealed by the in vitro and in vivo studies conducted so far.

In light of the current knowledge linking exposure to PM, where UFP play a major role, to the etiology of malignant and cardiovascular diseases, implementation of effective risk mitigation measures for protecting workers from (un)intentional exposure to ENP and ANP is of paramount importance in ceramic industrial settings. Health authorities, researchers, occupational health professionals and workers should cooperate to establish the most appropriate strategies to prevent and mitigate NP exposure. WHO preconizes the adoption of a precautionary approach that seek to minimize exposure to NM. Some of the recommendations to do so include assessing workers' exposure in workplaces and evaluating whether it exceeds a proposed OEL value for the specific $\mathrm{NM}$, reduction of exposures to a range of NM that have been consistently detected in workplaces, control measures based on the principle of hierarchy of controls (i.e elimination of the source of exposure before implementing control measures that are more worker-dependent, with protective PPE being used only as a last resort). Finally, the importance of providing data on exposure and efficiency of protective measures in industrial scenarios should be highlighted, in order to help policy-makers to establish a realistic OEL, that is, with a good balance between adequate worker's health protection and achievable OEL using the current available technologies.

\section{Acknowledgments}

The authors would like to acknowledge the contribution of COST Action CA15129 on Diagnosis, Monitoring and Prevention of Exposure-Related Noncommunicable Diseases (DiMoPEx).

\section{Conflicts of interest}

The authors declare that they have no competing interests. 


\section{Figure and Tables captions}

Figure 1. Main stages of the manufacturing process of ceramic products (Adapted from European Commission (2007)).

Figure 2. Overview of potential scenarios of intentional and/or unintentional workplace exposure to nanoparticles in the ceramic industry.

Table 1. List of raw materials commonly used in the ceramic industry.

Table 2. Existing methods and instruments used for airborne nanoparticle quantification.

Table 3. Provisional Nano Reference Values (NRV) for four classes of engineered nanoparticles (ENP) (Adapted from Social and Economic Council (2012)).

Table 4. Summary of the available case studies on ultrafine and airborne nanoparticle release and exposure in the ceramic industry. 


\section{Tables}

Table 1.

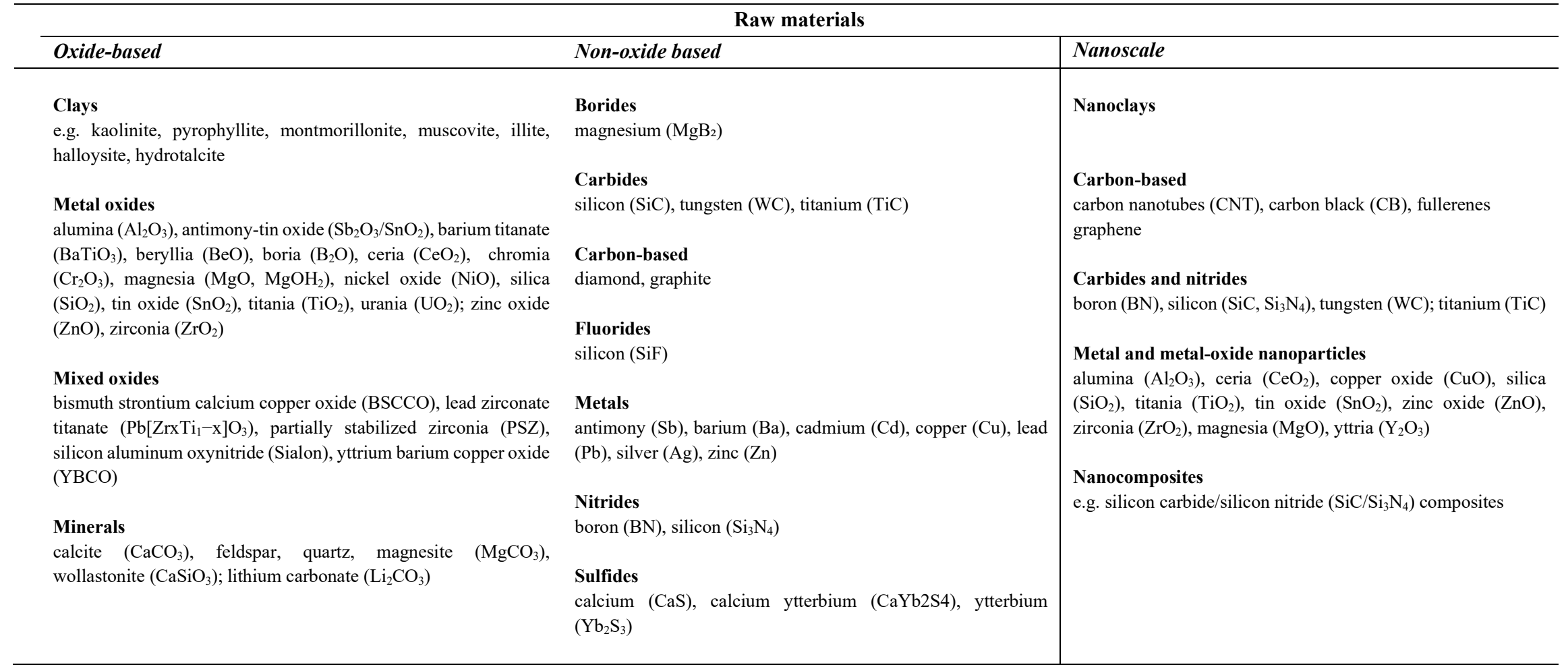


Table 2.

\begin{tabular}{|c|c|c|c|c|}
\hline & Parameters & $\begin{array}{l}\text { Stationary } \\
\text { equipment }\end{array}$ & $\begin{array}{c}\text { Portable } \\
\text { equipment }\end{array}$ & $\begin{array}{c}\text { Personal } \\
\text { equipment }\end{array}$ \\
\hline \multirow{4}{*}{ 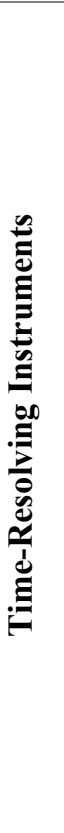 } & Particle number concentration & $\mathrm{CPC}$ & $\begin{array}{c}\text { Hand-held } \\
\text { CPC }\end{array}$ & \multirow{4}{*}{$\begin{array}{c}\text { DisCmini } \\
\text { Nano Tracer (e.g. } \\
\text { Aerasense } \\
\text { Nanoparticle } \\
\text { monitor) }\end{array}$} \\
\hline & Particle LDSA concentration & NSAM & $\begin{array}{c}\text { Downsize } \\
\text { NSAM }\end{array}$ & \\
\hline & Particle size distribution & $\begin{array}{c}\text { Electrical } \\
\text { mobility } \\
\text { analysis } \\
\text { (SMPS, } \\
\text { DMPS, } \\
\text { DMA) } \\
\text { and } \\
\text { Inertial } \\
\text { separation }\end{array}$ & $\begin{array}{l}\text { PAMS, } \\
\text { DMA }\end{array}$ & \\
\hline & Mean particle size & & & \\
\hline 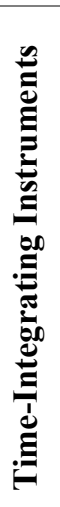 & Physicochemical analysis & $\begin{array}{c}\text { Filter sampling } \\
\text { Electrostatic } \\
\text { sampling }\end{array}$ & $\begin{array}{l}\text { Hand-held } \\
\text { ESPnano }\end{array}$ & $\begin{array}{c}\text { Thermophoretic } \\
\text { sampling (thermal } \\
\text { precipitator sampler) } \\
\text { Sampling on } \\
\text { different filtration } \\
\text { media (PENS, } \\
\text { NanoBadge, } \\
\text { Personal NRD) }\end{array}$ \\
\hline
\end{tabular}

Condensation Particle Counter (CPC); Nanoparticle Surface Area Monitor (NSAM); Scanning Mobility Particle Sizer (SMPS); Differential Mobility Particle Sizer (DMPS); Differential Mobility Analyser (DMA); Portable Aerosol Mobility Spectrometer (PAMS); Personal Nanoparticle Sampler (PENS); Nanoparticle Respiratory Deposition (NRD). 
Table 3.

\begin{tabular}{|c|c|c|}
\hline Type of Nanomaterial (NM) & $\begin{array}{l}\text { Nano Reference Value (NRV) } \\
\text { (for long-term exposure) }\end{array}$ & Examples \\
\hline Rigid, biopersistent nanofibres & 0.01 fibres. $\mathrm{cm}^{-3}$ & $\begin{array}{l}\text { Carbon nanotubes, metal oxide } \\
\text { fibres }\end{array}$ \\
\hline 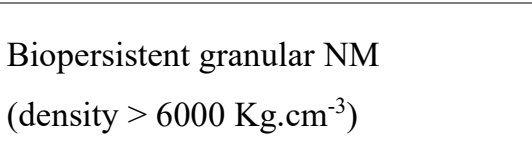 & 20000 particles. $\mathrm{cm}^{-3}$ & $\begin{array}{l}\text { Silver, gold, cerium oxide, cobalt } \\
\text { oxide, iron/iron oxide, lead, } \\
\text { antimony pentoxide, tin oxide }\end{array}$ \\
\hline $\begin{array}{l}\text { Biopersistent granular and fibre from } \\
\text { NM } \\
\left(\text { density }<6000 \mathrm{Kg} \mathrm{cm}^{-3}\right)\end{array}$ & 40000 particles. $\mathrm{cm}^{-3}$ & $\begin{array}{l}\text { Aluminium oxide, silicon oxide, } \\
\text { tin, titanium oxide, zinc oxide, } \\
\text { nanoclay }\end{array}$ \\
\hline Non-biopersistent granular NM & Applicable OEL & e.g. Sodium chloride \\
\hline
\end{tabular}


Table 4.

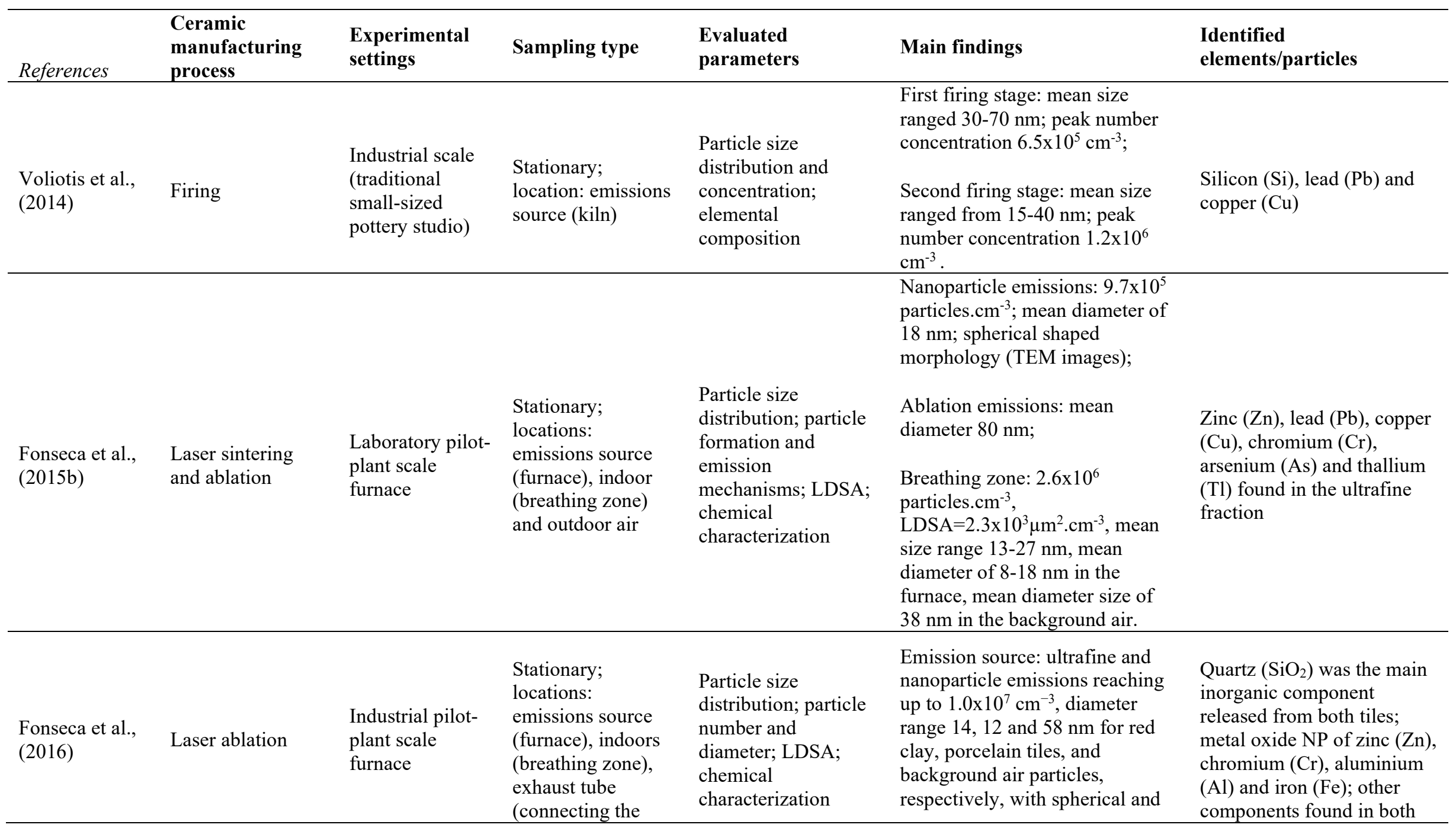




\begin{tabular}{|c|c|c|c|c|c|c|}
\hline & & & \multicolumn{2}{|l|}{$\begin{array}{l}\text { emission source to } \\
\text { outdoor air) }\end{array}$} & \multirow{2}{*}{$\begin{array}{l}\text { irregularly shaped morphologies } \\
\text { (TEM images); } \\
\text { Exposure concentrations to } \\
\text { ultrafine and nanoparticles } \\
\text { generated in this workplace } \\
\text { would exceed the NRV. }\end{array}$} & \multirow[t]{2}{*}{$\begin{array}{l}\text { tiles: calcium carbonate } \\
\left(\mathrm{CaCO}_{3}\right), \text { zinc oxide }(\mathrm{ZnO})\end{array}$} \\
\hline & & & & & & \\
\hline $\begin{array}{l}\text { Viana et al., } \\
(2017)\end{array}$ & $\begin{array}{l}\text { Atmospheric } \\
\text { plasma spraying }\end{array}$ & $\begin{array}{l}\text { Industrial pilot- } \\
\text { plant scale } \\
\text { furnace }\end{array}$ & $\begin{array}{l}\text { Stationary; } \\
\text { locations: inside } \\
\text { (worker's room) } \\
\text { and outside } \\
\text { spraying chamber, } \\
\text { outdoor air }\end{array}$ & $\begin{array}{l}\text { Particle size } \\
\text { distributions; particle } \\
\text { number, mass and } \\
\text { concentrations; } \\
\text { LDSA }\end{array}$ & $\begin{array}{l}\text { Inside the spraying chamber: } \\
\text { ultrafine emissions concentration } \\
\text { up to } 3.7 \times 10^{6} \mathrm{~cm}^{-3} \text {, diameter } \\
\text { range } 28-45 \mathrm{~nm} \text {, spherical and } \\
\text { irregularly shaped morphologies } \\
\text { (TEM images); } \\
\text { Worker area (potential breathing } \\
\text { zone): } 2.0 \times 10^{6} \mathrm{~cm}^{-3} \text {, diameter } \\
\text { range } 33-48 \mathrm{~nm} \text {; }\end{array}$ & $\begin{array}{l}\mathrm{ZrO}_{2}-\mathrm{Y}_{2} \mathrm{O}_{3} \text { nanoparticles, } \\
\text { gadolinium }(\mathrm{Gd}) \text { based } \\
\text { engineered nanoparticles, } \\
\text { mineral }(\mathrm{Ca}) \text { particles }\end{array}$ \\
\hline & & & & & $\begin{array}{l}\text { Ultrafine emissions were mainly } \\
\text { process-related. }\end{array}$ & \\
\hline $\begin{array}{l}\text { Salmatonidis et } \\
\text { al., (2018) }\end{array}$ & $\begin{array}{l}\text { Laser ablation } \\
\text { (two different } \\
\text { laser setups: near- } \\
\text { IR and mid-IR) }\end{array}$ & $\begin{array}{l}\text { Laboratory and } \\
\text { pilot-plant scale }\end{array}$ & $\begin{array}{l}\text { Stationary; } \\
\text { locations: emission } \\
\text { source, near-field, } \\
\text { far-field, outdoor } \\
\text { air }\end{array}$ & $\begin{array}{l}\text { Particle size, number } \\
\text { and mass } \\
\text { concentration; } \\
\text { chemical } \\
\text { characterization }\end{array}$ & $\begin{array}{l}\text { High particle number } \\
\text { concentrations were detected } \\
\left(3.5 \times 10^{4} \mathrm{~cm}^{-3} \text { to } 2.5 \times 10^{6} \mathrm{~cm}^{-3}\right) \\
\text { for all types of tiles and under } \\
\text { both laser setups; } \\
\text { Spherical shape; } \\
\text { Particle number and mass } \\
\text { emissions were dependent on the } \\
\text { tile surface characteristics and } \\
\text { chemical properties. }\end{array}$ & Silica $\left(\mathrm{SiO}_{2}\right)$ nanoparticles \\
\hline $\begin{array}{l}\text { Salmatonidis et } \\
\text { al., (2019a) }\end{array}$ & $\begin{array}{l}\text { Thermal spraying } \\
\text { coating }\end{array}$ & Industrial scale & $\begin{array}{l}\text { Stationary; } \\
\text { locations: near- } \\
\text { field (inside }\end{array}$ & $\begin{array}{l}\text { Particle size } \\
\text { distribution; }\end{array}$ & $\begin{array}{l}\text { Inside spraying booths: high } \\
\text { particle number }\left(>10^{6} \mathrm{~cm}^{-3} ; 30-\right. \\
40 \mathrm{~nm}) \text { and mass }(60-600 \\
\left.\mu \mathrm{gPM} 1 \mathrm{~m}^{-3}\right) \text { concentration }\end{array}$ & $\begin{array}{l}\text { Metal-containing particles: } \\
\text { nickel }(\mathrm{Ni}) \text {, chromium }(\mathrm{Cr}) \text {, } \\
\text { tungsten }(\mathrm{W})\end{array}$ \\
\hline
\end{tabular}




\begin{tabular}{|c|c|c|c|c|c|c|}
\hline & & & $\begin{array}{l}\text { spraying booths), } \\
\text { far-field }\end{array}$ & $\begin{array}{l}\text { Particle number } \\
\text { concentration, size- } \\
\text { segregated mass } \\
\text { concentrations; } \\
\text { LDSA }\end{array}$ & $\begin{array}{l}\text { Worker area: } 10^{4}-10^{5} \cdot \mathrm{cm}^{-3} \\
\text { particle number, } 40-65 \mathrm{~nm} \text { and } \\
44-87 \mu \mathrm{g} \text { PM1.m }{ }^{-3} \text { mass } \\
\text { concentration; } \\
\text { Irregularly-shaped nanoparticles } \\
\text { with small diameters were } \\
\text { detected inside }(31-41 \mathrm{~nm}) \text { and } \\
\text { outside ( } 40-64 \mathrm{~nm}) \text { the spraying } \\
\text { booths; } \\
\text { Inhaled dose rates: } 353 \times 10^{6}- \\
1024 \times 10^{6} \cdot \text { min }^{-1} \text {, with } 70 \% \text { of } \\
\text { deposition occurring in the } \\
\text { alveolar region. }\end{array}$ & \\
\hline $\begin{array}{l}\text { Ribalta et al., } \\
\text { (2019a) }\end{array}$ & $\begin{array}{l}\text { Handling of } \\
\text { powder materials }\end{array}$ & Pilot-plant & $\begin{array}{l}\text { Stationary and } \\
\text { personal; locations: } \\
\text { worker area } \\
\text { (breathing zone), } \\
\text { indoor, outdoor }\end{array}$ & $\begin{array}{l}\text { Particle mass and } \\
\text { number } \\
\text { concentration; } \\
\text { LDSA; chemical } \\
\text { characterization }\end{array}$ & $\begin{array}{l}\text { Particle number concentration } \\
\text { during handling: } 15 \text { 033-40 } 498 . \\
\mathrm{cm}^{-3} \text {, different particle shape } \\
\text { (prismatic and platy) (TEM } \\
\text { images); } \\
\text { LDSA during background: } 27- \\
101 \mu \mathrm{m}^{2} . \mathrm{cm}^{-3} \text {; LDSA during } \\
\text { materials handling: } 22-42 \mu \mathrm{m}^{2} \text {. } \\
\mathrm{cm}^{-3} \text {; } \\
\text { High degree of correlation } \\
\text { between dustiness and exposure } \\
\text { concentrations was found during } \\
\text { handling. }\end{array}$ & $\begin{array}{l}\text { Silicon }(\mathrm{Si}) \text {, aluminium } \\
(\mathrm{Al}) \text {, iron }(\mathrm{Fe}) \text {, oxygen }(\mathrm{O}) \text {, } \\
\text { calcium }(\mathrm{Ca}) \\
\text { Silica }\left(\mathrm{SiO}_{2}\right) \text { nanoparticles }\end{array}$ \\
\hline $\begin{array}{l}\text { Ribalta et al., } \\
(2019 b)\end{array}$ & $\begin{array}{l}\text { Packaging of raw } \\
\text { materials }\end{array}$ & Industrial scale & $\begin{array}{l}\text { Stationary and } \\
\text { personal; locations: } \\
\text { three packing lines }\end{array}$ & $\begin{array}{l}\text { Particle mass and } \\
\text { number } \\
\text { concentrations; } \\
\text { LDSA }\end{array}$ & $\begin{array}{l}\text { LDSA during packaging: } 5.4- \\
11.8 \times 10^{5} \mu \mathrm{m}^{2} . \mathrm{min}^{-1} \\
\text { Particles depositing mainly in the } \\
\text { alveoli }(51-64 \%) \text { followed by }\end{array}$ & $\begin{array}{l}\text { Silica }\left(\mathrm{SiO}_{2}\right) \text {, aluminia } \\
\left(\mathrm{Al}_{2} \mathrm{O}_{3}\right) \text {, iron oxide }\left(\mathrm{Fe}_{2} \mathrm{O}_{3}\right) \text {, } \\
\text { titania }\left(\mathrm{TiO}_{2}\right) \text {, potassium } \\
\text { oxide }\left(\mathrm{K}_{2} \mathrm{O}\right) \text {, magnesium } \\
\text { oxide }(\mathrm{MgO}) \text {, sodium oxide }\end{array}$ \\
\hline
\end{tabular}


(1) airways $(27-41 \%)$ and

trachea bronchi $(7-10 \%)$.

$\left(\mathrm{Na}_{2} \mathrm{O}\right)$, calcium oxide

$(\mathrm{CaO})$, lithium oxide $\left(\mathrm{Li}_{2} \mathrm{O}\right)$

Lung Deposited Surface Area (LDSA); Nano Reference Value (NRV); Infrared (IR), Transmission Electron Microscopy (TEM). 


\section{Figures}

\section{Figure 1}

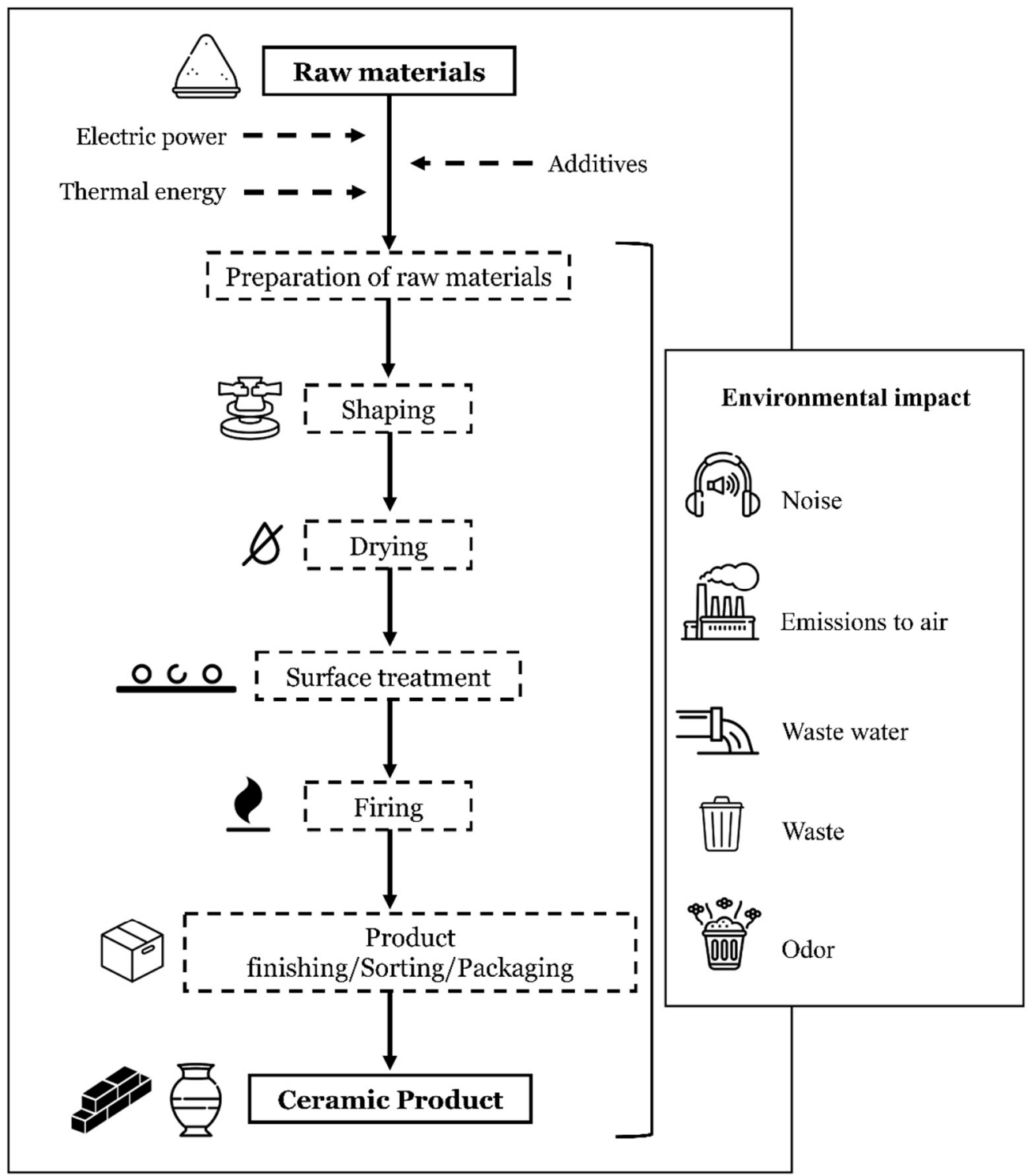




\section{Figure 2}

\section{Workplace exposure to (nano)particles in the ceramic industry}

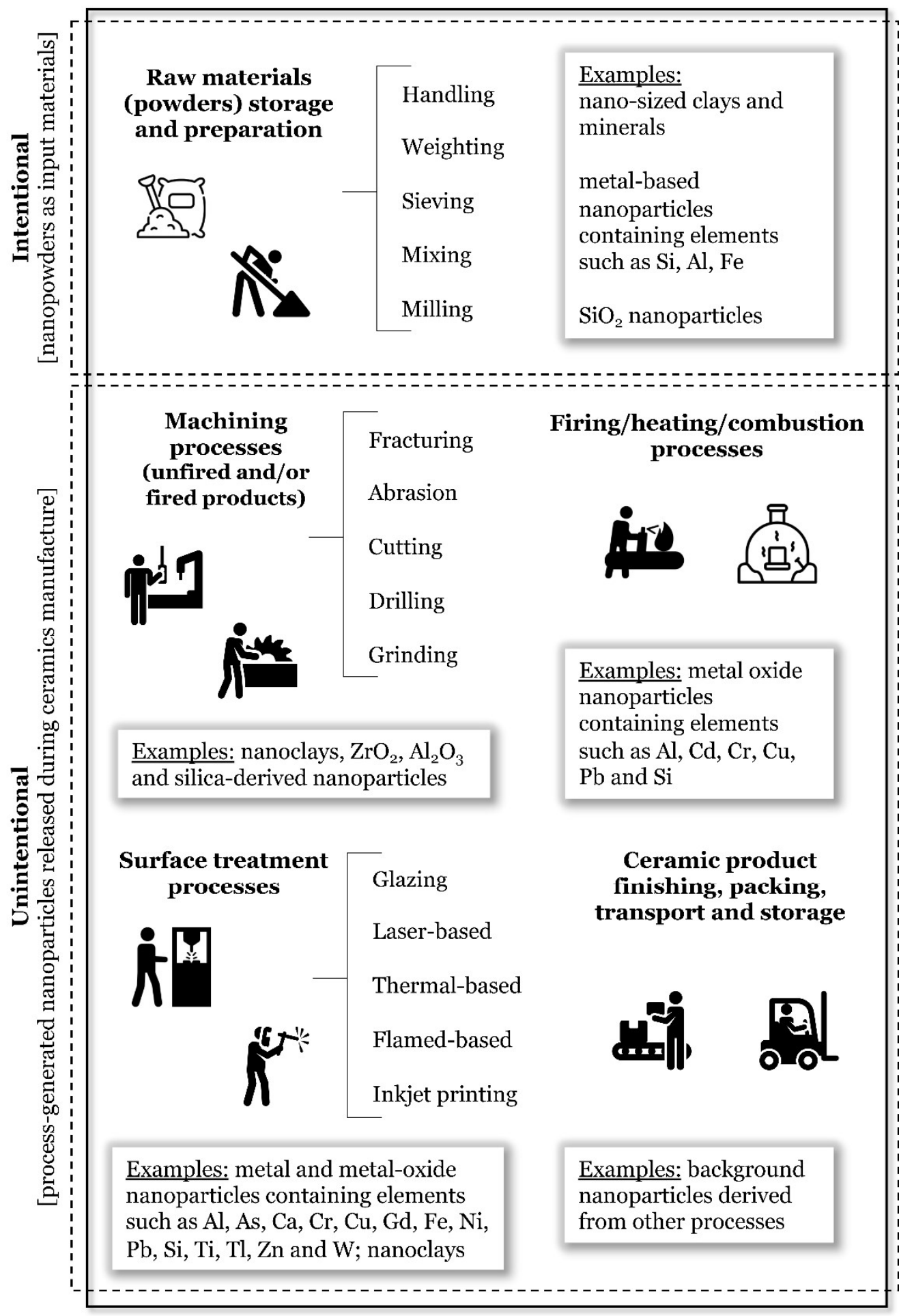




\section{References}

Ahamed, M., et al., 2010. Genotoxic potential of copper oxide nanoparticles in human lung epithelial cells. Biochemical and biophysical research communications. 396, 578-583.

Ahmad, I., et al., 2015. Recent Advances on Carbon Nanotubes and Graphene Reinforced Ceramics Nanocomposites. Nanomaterials (Basel). 5, 90-114.

Aitken, R., et al., 2004. Nanoparticles: An occupational hygiene review. HSE Books.

Akhtar, M. J., et al., 2010. Nanotoxicity of pure silica mediated through oxidant generation rather than glutathione depletion in human lung epithelial cells. Toxicology. 276, 95-102.

Arts, J. H., et al., 2007. Five-day inhalation toxicity study of three types of synthetic amorphous silicas in Wistar rats and post-exposure evaluations for up to 3 months. Food and chemical toxicology. 45, 1856-1867.

Asbach, C., et al., 2017. Review of measurement techniques and methods for assessing personal exposure to airborne nanomaterials in workplaces. Science of the Total Environment. 603, 793-806.

Baan, R. A., 2007. Carcinogenic hazards from inhaled carbon black, titanium dioxide, and talc not containing asbestos or asbestiform fibers: recent evaluations by an IARC Monographs Working Group. Inhalation Toxicology. 19, 213-228.

Bakand, S., et al., 2012. Nanoparticles: a review of particle toxicology following inhalation exposure. Inhalation Toxicology. 24, 125-135.

Barros, M. C., et al., 2007. Integrated pollution prevention and control for heavy ceramic industry in Galicia (NW Spain). J Hazard Mater. 141, 680-692.

Bozsin, M., Environmental Challenges for the Ceramic Industry. Ceramic Engineering and Science. Springer, 1974, pp. 93-101.

Brook, R. D., et al., 2004. Air pollution and cardiovascular disease: a statement for healthcare professionals from the Expert Panel on Population and Prevention Science of the American Heart Association. Circulation. 109, 2655-2671.

Brunner, T. J., et al., 2006. In vitro cytotoxicity of oxide nanoparticles: comparison to asbestos, silica, and the effect of particle solubility. Environmental science \& technology. 40, 43744381.

Cain, M., Morrell, R., 2001. Nanostructured ceramics: a review of their potential. Applied Organometallic Chemistry. 15, 321-330.

Cerame-Unie, 2012. The ceramic industry roadmap: paving the way to 2050. https://www.ceramfed.co.uk/.

Cerame-Unie, 2015. Cerame-Unie 2015 Annual Report. http://cerameunie.eu/.

Cho, W.-S., et al., 2007. Inflammatory mediators induced by intratracheal instillation of ultrafine amorphous silica particles. Toxicology letters. 175, 24-33. 
Cho, W. S., et al., 2012. Differential pro-inflammatory effects of metal oxide nanoparticles and their soluble ions in vitro and in vivo; zinc and copper nanoparticles, but not their ions, recruit eosinophils to the lungs. Nanotoxicology. 6, 22-35.

Chuang, H. C., et al., 2014. Cardiopulmonary toxicity of pulmonary exposure to occupationally relevant zinc oxide nanoparticles. Nanotoxicology. 8, 593-604.

Clippinger, A. J., et al., 2016. Expert consensus on an in vitro approach to assess pulmonary fibrogenic potential of aerosolized nanomaterials. Archives of Toxicology. 90, 1769-83.

Cronholm, P., et al., 2013. Intracellular uptake and toxicity of $\mathrm{Ag}$ and $\mathrm{CuO}$ nanoparticles: a comparison between nanoparticles and their corresponding metal ions. Small. 9, 970-982.

da Silva, A. L., et al., 2017. Self-cleaning ceramic tiles coated with Nb2O5-doped-TiO2 nanoparticles. Ceramics International. 43, 11986-11991.

De Marzi, L., et al., 2013. Cytotoxicity and genotoxicity of ceria nanoparticles on different cell lines in vitro. Int J Mol Sci. 14, 3065-3077.

Decan, N., et al., 2016. Characterization of in vitro genotoxic, cytotoxic and transcriptomic responses following exposures to amorphous silica of different sizes. Mutation Research/Genetic Toxicology and Environmental Mutagenesis. 796, 8-22.

Dolez, P. I., Debia, M., Overview of Workplace Exposure to Nanomaterials. Nanoengineering. Elsevier, 2015, pp. 427-484.

Donaldson, K., et al., 2013. Pulmonary toxicity of carbon nanotubes and asbestos - similarities and differences. Advanced Drug Delivery Reviews. 65, 2078-2086.

Donaldson, K., et al., 2005. Combustion-derived nanoparticles: a review of their toxicology following inhalation exposure. Part Fibre Toxicol. 2, 10.

Eom, H. J., Choi, J., 2009a. Oxidative stress of CeO2 nanoparticles via p38-Nrf-2 signaling pathway in human bronchial epithelial cell, Beas-2B. Toxicol Lett. 187, 77-83.

Eom, H. J., Choi, J., 2009b. Oxidative stress of silica nanoparticles in human bronchial epithelial cell, Beas-2B. Toxicol In Vitro. 23, 1326-1332.

European Commission, Reference Document on Best Available Techniques in the Ceramic Manufacturing Industry. 2007.

European Commission, 2011. Commission Recommendation of 18 October 2011 on the definition of nanomaterial. Official Journal of the European Union. 275, 38.

Fahmy, B., Cormier, S. A., 2009. Copper oxide nanoparticles induce oxidative stress and cytotoxicity in airway epithelial cells. Toxicol In Vitro. 23, 1365-1371.

Fonseca, A., et al., Workplace Exposure to Process-Generated Ultrafine and Nanoparticles in Ceramic Processes Using Laser Technology. Indoor and Outdoor Nanoparticles. Springer, 2015a, pp. 159-179.

Fonseca, A. S., et al., 2016. Process-generated nanoparticles from ceramic tile sintering: Emissions, exposure and environmental release. Sci. Total Environ. 565, 922-932. 
Fonseca, A. S., et al., 2015b. Ultrafine and nanoparticle formation and emission mechanisms during laser processing of ceramic materials. Journal of Aerosol Science. 88, 48-57.

Fröhlich, E., Salar-Behzadi, S., 2014. Toxicological assessment of inhaled nanoparticles: role of in vivo, ex vivo, in vitro, and in silico studies. International journal of molecular sciences. $15,4795-4822$.

Gandra, J., et al., 2011. Functionally graded materials produced by friction stir processing. Journal of Materials Processing Technology. 211, 1659-1668.

Geiss, O., et al., 2016. Lung-deposited surface area concentration measurements in selected occupational and non-occupational environments. Journal of Aerosol Science. 96, 24-37.

Gosens, I., et al., 2016. Organ burden and pulmonary toxicity of nano-sized copper (II) oxide particles after short-term inhalation exposure. Nanotoxicology. 10, 1084-1095.

Guichard, Y., et al., 2015. Genotoxicity of synthetic amorphous silica nanoparticles in rats following short-term exposure. Part 2: intratracheal instillation and intravenous injection. Environmental and Molecular Mutagenesis. 56, 228-244.

Hämeri, K., et al., 2009. Facing the key workplace challenge: Assessing and preventing exposure to nanoparticles at source. Inhalation Toxicology. 21, 17-24.

Heal, M. R., et al., 2012. Particles, air quality, policy and health. Chemical Society Reviews. 41, 6606-6630.

Hodson, L., et al., 2009. Approaches to safe nanotechnology; managing the health and safety concerns associated with engineered nanomaterials. Centers for Disease Control and Prevention \& National Institute for Occupational Safety and Health.

Horie, M., et al., 2011. Evaluation of acute oxidative stress induced by $\mathrm{NiO}$ nanoparticles in vivo and in vitro. Journal of occupational health. 53, 64-74.

Horie, M., et al., 2009. Ultrafine $\mathrm{NiO}$ particles induce cytotoxicity in vitro by cellular uptake and subsequent $\mathrm{Ni}$ (II) release. Chemical research in toxicology. 22, 1415-1426.

Hristozov, D., Malsch, I., 2009. Hazards and risks of engineered nanoparticles for the environment and human health. Sustainability. 1, 1161-1194.

International Agency for Research on Cancer, 2012. Arsenic, metals, fibres, and dusts. Volume 100 C. A review of human carcinogens. IARC Monographs on the Evaluation of Carcinogenic Risks to Humans. Lyon (FR): International Agency for Research on Cancer, Arsenic and arsenic compounds. 41-94.

Irvin, C. G., Bates, J. H., 2003. Measuring the lung function in the mouse: the challenge of size. Respiratory research. $4,4$.

Ivask, A., et al., 2015. Toxicity of 11 metal oxide nanoparticles to three mammalian cell types in vitro. Current topics in medicinal chemistry. 15, 1914-1929.

Jaakkola, M. S., et al., 2011. Effects of occupational exposures and smoking on lung function in tile factory workers. Int. Arch. Occup. Environ. Health. 84, 151-158. 
Journeay, W. S., Goldman, R. H., 2014. Occupational handling of nickel nanoparticles: a case report. Am J Ind Med. 57, 1073-1076.

Kargar, F., et al., 2013. Evaluation of occupational exposure of glazers of a ceramic industry to cobalt blue dye. Iranian journal of public health. 42, 868.

Karlsson, H. L., et al., 2008. Copper oxide nanoparticles are highly toxic: a comparison between metal oxide nanoparticles and carbon nanotubes. Chemical research in toxicology. 21, 1726-1732.

Kayat, J., et al., 2011. Pulmonary toxicity of carbon nanotubes: a systematic report. Nanomedicine. 7, 40-49.

Keller, J., et al., 2014. Time course of lung retention and toxicity of inhaled particles: short-term exposure to nano-Ceria. Archives of Toxicology. 88, 2033-2059.

Kelly, F. J., Fussell, J. C., 2015. Air pollution and public health: emerging hazards and improved understanding of risk. Environmental geochemistry and health. 37, 631-649.

Kim, I.-S., et al., 2010. Comparative cytotoxicity of A12O3, CeO2, TiO2 and $\mathrm{ZnO}$ nanoparticles to human lung cells. Journal of Nanoscience and Nanotechnology. 10, 3453-3458.

Knaapen, A. M., et al., 2004. Inhaled particles and lung cancer. Part A: Mechanisms. International Journal of Cancer. 109, 799-809.

Knuuttila, J., et al., Wet abrasion and slurry erosion resistance of sealed oxide coatings. Proceedings of the 15 th International Thermal spray conference, Vol. 1, 1998, pp. 145150.

Kobayashi, N., et al., 2017. Review of toxicity studies of carbon nanotubes. Journal of occupational health. 59, 394-407.

Kreyling, W. G., et al., 2006. Health implications of nanoparticles. Journal of nanoparticle research. 8, 543-562.

Kuhlbusch, T. A., et al., 2011. Nanoparticle exposure at nanotechnology workplaces: a review. Part. Fibre Toxicol. 8, 22.

Kuper, C. F., et al., 2015. Toxicity assessment of aggregated/agglomerated cerium oxide nanoparticles in an in vitro 3D airway model: The influence of mucociliary clearance. Toxicology in Vitro. 29, 389-397.

Lacroix, G., et al., 2018. Air-Liquid Interface In Vitro Models for Respiratory Toxicology Research: Consensus Workshop and Recommendations. Applied In Vitro Toxicology. 4, 91-106.

Lanone, S., et al., 2009. Comparative toxicity of 24 manufactured nanoparticles in human alveolar epithelial and macrophage cell lines. Particle and Fibre Toxicology. 6, 14.

Lee, J., et al., 2010. Nanomaterials in the construction industry: a review of their applications and environmental health and safety considerations. ACS nano. 4, 3580-3590.

Leung, C. C., et al., 2012. Silicosis. The Lancet. 379, 2008-2018. 
Li, J. J. e., et al., 2010. Nanoparticle-induced pulmonary toxicity. Experimental biology and medicine. 235, 1025-1033.

Liguori, B., et al., 2016. Control banding tools for occupational exposure assessment of nanomaterials - Ready for use in a regulatory context? NanoImpact. 2, 1-17.

Lin, W., et al., 2006a. In vitro toxicity of silica nanoparticles in human lung cancer cells. Toxicol Appl Pharmacol. 217, 252-259.

Lin, W., et al., 2006b. Toxicity of cerium oxide nanoparticles in human lung cancer cells. Int $\mathbf{J}$ Toxicol. 25, 451-457.

Lindberg, H. K., et al., 2012. Genotoxicity of inhaled nanosized TiO2 in mice. Mutation Research/Genetic Toxicology and Environmental Mutagenesis. 745, 58-64.

Liu, J., et al., 2016. Effects of pore structure on thermal conductivity and strength of alumina porous ceramics using carbon black as pore-forming agent. Ceramics International. 42, $8221-8228$

Ma, J. Y., et al., 2011. Cerium oxide nanoparticle-induced pulmonary inflammation and alveolar macrophage functional change in rats. Nanotoxicology. 5, 312-325.

Magdolenova, Z., et al., 2012. Can standard genotoxicity tests be applied to nanoparticles? Journal of Toxicology and Environmental Health, Part A. 75, 800-806.

Manivasakan, P., et al., 2010. Effect of TiO2 Nanoparticles on Properties of Silica Refractory. Journal of the American Ceramic Society. 93, 2236-2243.

Manke, A., et al., 2014. Potential Occupational Risks Associated with Pulmonary Toxicity of Carbon Nanotubes. Occupational Medicine and Health Affairs 2, 1000165.

Marinescu, I. D., 2006. Handbook of advanced ceramics machining. CRC Press.

Maser, E., et al., 2015. In vitro and in vivo genotoxicity investigations of differently sized amorphous $\mathrm{SiO} 2$ nanomaterials. Mutation Research/Genetic Toxicology and Environmental Mutagenesis. 794, 57-74.

Maynard, A. D., Kuempel, E. D., 2005. Airborne nanostructured particles and occupational health. Journal of nanoparticle research. 7, 587-614.

McCarthy, J., et al., 2012. Mechanisms of toxicity of amorphous silica nanoparticles on human lung submucosal cells in vitro: protective effects of fisetin. Chem Res Toxicol. 25, 22272235.

Midander, K., et al., 2009. Surface characteristics, copper release, and toxicity of nano- and micrometer-sized copper and copper(II) oxide particles: a cross-disciplinary study. Small. 5, 389-399.

Mihalache, R., et al., 2017. Occupational exposure limits for manufactured nanomaterials, a systematic review. Nanotoxicology. 11, 7-19. 
Monfort, E., et al., Control of fugitive particulate emissions in the ceramic industry. Qualicer 2006: IX World Congress on Ceramic Tile Quality, Castellón, Cámara oficial de comercio, industria y navegación, 2006, pp. PBC 137-PBC 150.

Mon-fort, E., et al., 2014. La evolu-ción en-ergética del sec-tor es-pañol de bal-dosas cerámi-cas. Boletín de la Sociedad Española de Cerámica y Vidrio 53, 111-120.

Mulware, S. J., 2013. Trace elements and carcinogenicity: a subject in review. 3 Biotech. 3, 8596.

Munz, D., Fett, T., 2013. Ceramics: mechanical properties, failure behaviour, materials selection. Springer Science \& Business Media.

Murugadoss, S., et al., 2017. Toxicology of silica nanoparticles: an update. Archives of Toxicology. 91, 2967-3010.

Nagai, H., et al., 2011. Diameter and rigidity of multiwalled carbon nanotubes are critical factors in mesothelial injury and carcinogenesis. Proceedings of the National Academy of Sciences. 108, E1330-E1338.

Nagai, H., Toyokuni, S., 2012. Differences and similarities between carbon nanotubes and asbestos fibers during mesothelial carcinogenesis: shedding light on fiber entry mechanism. Cancer science. 103, 1378-1390.

Naya, M., et al., 2012. In vivo genotoxicity study of titanium dioxide nanoparticles using comet assay following intratracheal instillation in rats. Regulatory Toxicology and Pharmacology. 62, 1-6.

Noël, A., Truchon, G., 2015. Inhaled Titanium Dioxide Nanoparticles: A Review of Their Pulmonary Responses with Particular Focus on the Agglomeration State. Nano LIFE. 05.

O'Shaughnessy, P. T., 2013. Occupational health risk to nanoparticulate exposure. Environ. Sci. Processes Impacts. 15, 49-62.

Oberdörster, G., 2000. Pulmonary effects of inhaled ultrafine particles. International archives of occupational and environmental health. 74, 1-8.

Oberdörster, G., 2010. Safety assessment for nanotechnology and nanomedicine: concepts of nanotoxicology. Journal of internal medicine. 267, 89-105.

Oberdorster, G., et al., 2005. Principles for characterizing the potential human health effects from exposure to nanomaterials: elements of a screening strategy. Part. Fibre Toxicol. 2, 8.

Oberdörster, G., et al., 2005. Nanotoxicology: An Emerging Discipline Evolving from Studies of Ultrafine Particles. Environmental Health Perspectives. 113, 823-839.

Oberdörster, G., et al., 2007. Concepts of nanoparticle dose metric and response metric. Environmental Health Perspectives. 115, A290-A290.

Palmero, P., 2015. Structural Ceramic Nanocomposites: A Review of Properties and Powders' Synthesis Methods. Nanomaterials (Basel). 5, 656-696.

Pampuch, R., 2014. An introduction to ceramics. Springer. 
Panas, A., et al., 2014. Silica nanoparticles are less toxic to human lung cells when deposited at the air-liquid interface compared to conventional submerged exposure. Beilstein $\mathrm{J}$ Nanotechnol. 5, 1590-1602.

Panas, A., et al., 2013. Screening of different metal oxide nanoparticles reveals selective toxicity and inflammatory potential of silica nanoparticles in lung epithelial cells and macrophages. Nanotoxicology. 7, 259-273.

Park, B., et al., 2008a. Hazard and risk assessment of a nanoparticulate cerium oxide-based diesel fuel additive - a case study. Inhal Toxicol. 20, 547-566.

Park, E. J., et al., 2008b. Oxidative stress induced by cerium oxide nanoparticles in cultured BEAS-2B cells. Toxicology. 245, 90-100.

Paur, H.-R., et al., 2011. In-vitro cell exposure studies for the assessment of nanoparticle toxicity in the lung - A dialog between aerosol science and biology. Journal of Aerosol Science. 42, 668-692.

Pavan, C., et al., 2019. The puzzling issue of silica toxicity: are silanols bridging the gaps between surface states and pathogenicity? Particle and Fibre Toxicology. 16, 1-10.

Pavan, C., Fubini, B., 2017. Unveiling the variability of "quartz hazard" in light of recent toxicological findings. Chemical research in toxicology. 30, 469-485.

Pietroiusti, A., Magrini, A., 2014. Engineered nanoparticles at the workplace: current knowledge about workers' risk. Occup. Med. (Lond). 64, 319-330.

Pietroiusti, A., et al., 2018. Nanomaterial exposure, toxicity, and impact on human health. Wiley Interdiscip Rev Nanomed Nanobiotechnol. 10, e1513.

Poinen-Rughooputh, S., et al., 2016. Occupational exposure to silica dust and risk of lung cancer: an updated meta-analysis of epidemiological studies. BMC public health. 16, 1137.

Rathod, V. T., et al., 2017. Polymer and ceramic nanocomposites for aerospace applications. Applied Nanoscience. 7, 519-548.

Reche, C., et al., 2015. Determinants of aerosol lung-deposited surface area variation in an urban environment. Sci. Total Environ. 517, 38-47.

Relier, C., et al., 2017. Study of TiO2 P25 nanoparticles genotoxicity on lung, blood, and liver cells in lung overload and non-overload conditions after repeated respiratory exposure in rats. Toxicological Sciences. 156, 527-537.

Ribalta, C., et al., 2019a. On the Relationship between Exposure to Particles and Dustiness during Handling of Powders in Industrial Settings. Ann Work Expo Health. 63, 107-123.

Ribalta, C., et al., 2019b. Health risk assessment from exposure to particles during packing in working environments. Sci Total Environ. 671, 474-487. Riediker, M., et al., 2019. Particle toxicology and health - where are we? Part Fibre Toxicol. 16, 19.

Roco, M. C., The long view of nanotechnology development: the National Nanotechnology Initiative at 10 years. Springer, 2011. 
Rothen-Rutishauser B, G. R., Blank F, Limbach LK, Mühlfeld C, Brandenberger C, Raemy DO, Gehr P, Stark WJ., 2009. Direct combination of nanoparticle fabrication and exposure to lung cell cultures in a closed setup as a method to simulate accidental nanoparticle exposure of humans. Environ Sci Technol. 43, 2634-2640.

Salmatonidis, A., et al., 2019a. Workplace Exposure to Nanoparticles during Thermal Spraying of Ceramic Coatings. Annals of Work Exposures and Health. 63, 91-106.

Salmatonidis, A., et al., 2019b. Effectiveness of nanoparticle exposure mitigation measures in industrial settings. International Journal of Hygiene and Environmental Health. 222, 926935.

Salmatonidis, A., et al., 2018. Nanoparticle formation and emission during laser ablation of ceramic tiles. Journal of Aerosol Science. 126, 152-168.

Sayes, C. M., et al., 2010. Changing the dose metric for inhalation toxicity studies: short-term study in rats with engineered aerosolized amorphous silica nanoparticles. Inhal Toxicol. 22, 348-354.

Schenk, L., Johanson, G., 2010. Use of uncertainty factors by the SCOEL in their derivation of health-based occupational exposure limits. Crit Rev Toxicol. 40, 791-8.

Schmid, O., Stoeger, T., 2016. Surface area is the biologically most effective dose metric for acute nanoparticle toxicity in the lung. Journal of Aerosol Science. 99, 133-143.

Schneider, T., et al., 2011. Conceptual model for assessment of inhalation exposure to manufactured nanoparticles. J. Expo. Sci. Environ. Epidemiol. 21, 450-463.

Schulte, P. A., et al., 2010. Occupational exposure limits for nanomaterials: state of the art. Journal of nanoparticle research. 12, 1971-1987.

Schulz, H., et al., 2005. Cardiovascular effects of fine and ultrafine particles. Journal of aerosol medicine. 18, 1-22.

Seipenbusch, M., et al., Chapter 4 - From Source to Dose: Emission, Transport, Aerosol Dynamics and Dose Assessment for Workplace Aerosol Exposure. In: U. Vogel, et al., Eds.), Handbook of Nanosafety. Academic Press, San Diego, 2014, pp. 135-171.

Shannahan, J. H., et al., 2012. Manufactured and airborne nanoparticle cardiopulmonary interactions: a review of mechanisms and the possible contribution of mast cells. Inhalation Toxicology. 24, 320-339.

Shi, H., et al., 2013. Titanium dioxide nanoparticles: a review of current toxicological data. Particle and Fibre Toxicology. 10, 15.

Shvedova, A. A., et al., 2009. Mechanisms of pulmonary toxicity and medical applications of carbon nanotubes: Two faces of Janus? Pharmacology \& Therapeutics. 121, 192-204.

Singh, A. K., 2015. Engineered nanoparticles: structure, properties and mechanisms of toxicity. Academic Press. 
Singh, D., et al., 2016. Ceramic nanoparticles: Recompense, cellular uptake and toxicity concerns.

Artif Cells Nanomed Biotechnol. 44, 401-409.

Srinivas, A., et al., 2011. Acute inhalation toxicity of cerium oxide nanoparticles in rats. Toxicol Lett. 205, 105-115.

Stebounova, L. V., et al., 2018. Particle Concentrations in Occupational Settings Measured with a Nanoparticle Respiratory Deposition (NRD) Sampler. Ann Work Expo Health. 62, 699710.

Stone, V., et al., 2017. Nanomaterials Versus Ambient Ultrafine Particles: An Opportunity to Exchange Toxicology Knowledge. Environ Health Perspect. 125, 106002.

Stueckle, T. A., et al., 2018. Short-Term Pulmonary Toxicity Assessment of Pre- and Postincinerated Organomodified Nanoclay in Mice. ACS nano. 12, 2292-2310.

$\mathrm{Su}$, W. C., et al., 2016. Deposition of graphene nanomaterial aerosols in human upper airways. Journal of Occupational and Environmental Hygiene. 13, 48-59.

Todea, A. M., et al., 2015. Accuracy of electrical aerosol sensors measuring lung deposited surface area concentrations. Journal of Aerosol Science. 89, 96-109.

Traykova, T., et al., 2006. Bioceramics as nanomaterials. Nanomedicine (Lond). 1, 91-106.

Trethowan, W., et al., 1995. Study of the respiratory health of employees in seven European plants that manufacture ceramic fibres. Occupational and Environmental Medicine. 52, 97-104.

Tsai, C.-J., et al., 2012. Novel active personal nanoparticle sampler for the exposure assessment of nanoparticles in workplaces. Environmental science \& technology. 46, 4546-4552.

Turci, F., et al., 2016. Revisiting the paradigm of silica pathogenicity with synthetic quartz crystals: the role of crystallinity and surface disorder. Particle and Fibre Toxicology. 13, 32.

Vallyathan, V., Gwinn, M. R., 2006. Nanoparticles: Health Effects-Pros and Cons. Environmental Health Perspectives. 1818-1825.

van Broekhuizen, P., et al., 2012a. Workplace exposure to nanoparticles and the application of provisional nanoreference values in times of uncertain risks. Journal of nanoparticle research. 14, 770.

van Broekhuizen, P., et al., 2012b. Exposure limits for nanoparticles: report of an international workshop on nano reference values. Ann. Occup. Hyg. 56, 515-524.

Viana, M., et al., 2017. Workplace exposure and release of ultrafine particles during atmospheric plasma spraying in the ceramic industry. Sci. Total Environ. 599-600, 2065-2073.

Vida, S., et al., 2010. Occupational exposure to silica and lung cancer: pooled analysis of two case-control studies in Montreal, Canada. Cancer Epidemiol Biomarkers Prev. 19, $1602-$ 11.

Voliotis, A., et al., 2014. Nanoparticle emissions from traditional pottery manufacturing. Environ. Sci. Process Impacts. 16, 1489-1494. 
Wagner, A., et al., 2017a. Toxicity evaluations of nanoclays and thermally degraded byproducts through spectroscopical and microscopical approaches. Biochim Biophys Acta Gen Subj. 1861, 3406-3415.

Wagner, A., et al., 2017b. Early Assessment and Correlations of Nanoclay's Toxicity to Their Physical and Chemical Properties. ACS Applied Materials \& Interfaces. 9, 32323-32335.

Wagner, A., et al., 2018. Incineration of nanoclay composites leads to byproducts with reduced cellular reactivity. Scientific reports. 8, 10709.

Wakamatsu, M., Salomao, R., 2010. Ceramic nanoparticles: what else do we have to know? International Ceramic Review. 59, 28-33.

Wang, Y., et al., 2009. Laser surface remelting of plasma sprayed nanostructured Al2O3-13wt $\%$ TiO2 coatings on titanium alloy. Applied Surface Science. 255, 8603-8610.

Wang, Z., et al., 2012. CuO nanoparticle interaction with human epithelial cells: cellular uptake, location, export, and genotoxicity. Chem Res Toxicol. 25, 1512-1521.

Ware, L. B., Modeling human lung disease in animals. American Physiological Society, 2008.

Wittmaack, K., 2006. In search of the most relevant parameter for quantifying lung inflammatory response to nanoparticle exposure: particle number, surface area, or what? Environmental Health Perspectives. 115, 187-194.

Wittmaack, K., 2007. Dose and Response Metrics in Nanotoxicology: Wittmaack Responds to Oberdoerster et al. and Stoeger et al. Environmental Health Perspectives. 115, A291A292.

World Health Organization, WHO Guidelines from potential risks on protecting workers of manufactured nanomaterials. 2017.

Woskie, S., 2010. Workplace practices for engineered nanomaterial manufacturers. Wiley Interdisciplinary Reviews: Nanomedicine and Nanobiotechnology. 2, 685-692.

Xia, T., et al., 2008. Comparison of the mechanism of toxicity of zinc oxide and cerium oxide nanoparticles based on dissolution and oxidative stress properties. ACS nano. 2, 21212134. 